\title{
Receptor binding peptides for target-selective delivery of nanoparticles encapsulated drugs
}

\author{
This article was published in the following Dove Press journal: \\ International Journal of Nanomedicine \\ 27 March 2014 \\ Number of times this article has been viewed
}

\author{
Antonella Accardo' \\ Luigi Aloj ${ }^{2}$ \\ Michela Aurilio² \\ Giancarlo Morelli' \\ Diego Tesauro' \\ 'Centro interuniversitario di Ricerca \\ sui Peptidi Bioattivi (CIRPeB), \\ Department of Pharmacy and Istituto \\ di Biostrutture e Bioimmagini - \\ Consiglio Nazionale delle Ricerche \\ (IBB CNR), University of Naples \\ "Federico II", ${ }^{2}$ Department of \\ Nuclear Medicine, Istituto Nazionale \\ per lo Studio e la Cura dei Tumori, \\ Fondazione "G. Pascale", Napoli, Italy
}

Correspondence: Diego Tesauro CIRPeB, Department of Pharmacy and IBB CNR, University of Naples "Federico II", Via Mezzocannone 16, 80 I 34 Napoli, Italy

Tel +39 08I 2536643

Email dtesauro@unina.it

\begin{abstract}
Active targeting by means of drug encapsulated nanoparticles decorated with targeting bioactive moieties represents the next frontier in drug delivery; it reduces drug side effects and increases the therapeutic index. Peptides, based on their chemical and biological properties, could have a prevalent role to direct drug encapsulated nanoparticles, such as liposomes, micelles, or hard nanoparticles, toward the tumor tissues. A considerable number of molecular targets for peptides are either exclusively expressed or overexpressed on both cancer vasculature and cancer cells. They can be classified into three wide categories: integrins; growth factor receptors (GFRs); and G-protein coupled receptors (GPCRs). Therapeutic agents based on nanovectors decorated with peptides targeting membrane receptors belonging to the GPCR family overexpressed by cancer cells are reviewed in this article. The most studied targeting membrane receptors are considered: somatostatin receptors; cholecystokinin receptors; receptors associated with the Bombesin like peptides family; luteinizing hormone-releasing hormone receptors; and neurotensin receptors. Nanovectors of different sizes and shapes (micelles, liposomes, or hard nanoparticles) loaded with doxorubicin or other cytotoxic drugs and externally functionalized with natural or synthetic peptides are able to target the overexpressed receptors and are described based on their formulation and in vitro and in vivo behaviors.
\end{abstract}

Keywords: receptors binding peptides, drug delivery, nanoparticles, supramolecular aggregates, active targeting

\section{Introduction}

Oral and intravenous administration of drugs is generally utilized for systemic treatment. Such methods deliver fixed concentrations of drugs to all organs and tissues in the body. In many cases, only a small amount of the administered molecules reaches the target organ. A challenge for drug therapy research is to selectively target drugs to diseased organs and tissues. This would allow more efficient use of drugs by achieving higher concentrations in target organs and lowering concentrations in remaining tissues, with a consequent reduction of side effects. This goal has pushed scientists to develop carriers capable of driving and localizing drugs. ${ }^{1}$

The pharmacokinetic and pharmacodynamic properties of the active drug thus become dependent on the pharmacokinetics of its carrier. A drug may be bound to the carrier covalently, through Van der Waals interactions, or it may be enclosed in supramolecular aggregates. For the latter option, the carrier also serves as a means for controlled drug release. Targeted drug delivery is appealing for application in a variety of diseases, such as cardiovascular disease ${ }^{2}$ and diabetes $;{ }^{3}$ however, the area of main interest for the application of these methods is in oncology, where concentration of the 
drug in tumor cells is a crucial issue. Most chemotherapeutic drugs target some aspect of cell proliferation to exert their therapeutic effect. Therefore, most side effects are linked to the activity of these drugs on normal tissues with rapid cell proliferation such as the bone marrow. ${ }^{4}$ Different strategies are being investigated in order to improve targeting of drugs to cancer cells. In passive targeting, increased delivery of the drug to target cells is achieved by taking advantage of the intrinsic properties of the tumor vasculature which permits an increase in the non-specific trapping of drugs, whereas active targeting is based on the use of tumor targeting bioactive compounds to drive drug accumulation.

\section{Passive targeting}

Matsumura and Maeda proposed that passive targeting may be exploited through a mechanism known as the Enhanced Permeability and Retention (EPR) effect. ${ }^{5}$ The EPR effect is based on enhanced vascular permeability in the tumor due to blood vessel overgrowth. It facilitates transport of macromolecules or nanoparticles into tumor tissues, allowing accumulation of drug-based nanomaterials on tumor cells and their retention for an extended period of time (days to weeks). In passive targeting, macromolecules of a certain size (10-500 nm) remain in circulation for an extended period of time and are taken up into cells by vesicular uptake processes (endocytosis). On the contrary, intravenously injected particles smaller than $5 \mathrm{~nm}$ are removed from the blood by rapid renal clearance through the kidneys, while very large microsized particles are filtered mechanically by the sinusoids and cleared by the reticuloendothelial system (RES) of the liver and spleen. Moreover, surface hydrophobicity and charged systems are more prone to opsonization and are consequently taken up by the RES, even when the size is within the specified limits. ${ }^{6}$ In contrast, neutral particles have a low opsonization.

The drug carriers that are most frequently utilized for this purpose are micelles and liposomes. Micelles (diameter range 5-50 nm) are composed of surfactant molecules dispersed in a liquid colloid. For drug delivery applications, polymeric micelles can be obtained by self-assembling amphiphilic copolymers in aqueous solution. These aggregates typically display a spherical structure, where the hydrophilic head of the composing monomers is in contact with the surrounding aqueous solution; hydrophobic tail regions are sequestered in the inner core. The densely packed core consists of hydrophobic blocks (less than 2,000 g/mol) while the shell consists of poly(ethylene oxide) (PEO). An adequately high number of PEO chains can prevent protein adsorption and cellular adhesion, steps which precede mononuclear phagocyte system (MPS) uptake in the RES extending blood-circulation time. Moreover, this polymer is inexpensive, has a low toxicity, and has been approved for internal applications by regulatory agencies. ${ }^{7}$ Poorly hydrophilic drugs can also be loaded in the micelle core. ${ }^{8}$

Polymeric micelles synthesized as biocompatible and biodegradable drug carriers include aggregates obtained with: 1) PEO-b-poly(P-benzyl-L-aspartate) (PEO-PBLA) ${ }^{9}$ 2) PEO-b-poly(L-lactic acid) (PEO-PLA); ${ }^{10}$ and 3) PEOlipid conjugates. Micelles of PEO-PBLA, PEO-PLA, and PEO lipid conjugates allow better dispersion of hydrophobic anticancer drugs such as taxol and etoposide. ${ }^{11}$ It is possible to tailor the cores of polymeric micelles in order to solubilize drugs of varying polarity, for example polymeric micelles having a poly(L-amino acid) core can take up and protect water-insoluble drugs. ${ }^{12,13}$ Controlled levels of doxorubicin (DOX), a hydrophilic anthracycline analog and one of the most frequently prescribed antineoplastic agents for cancer chemotherapy, have been successfully loaded into micelles of PEO-h-poly(aspartate $)^{14}$ or PEO-PBLA. ${ }^{15}$

Some other hydrophilic polymers may be used as hydrophilic blocks. ${ }^{16}$ Among possible alternatives to PEO, poly(N-vinyl-2-pyrrolidone) (PVP), which is highly biocompatible $^{17}$ and could be employed in diblock polymer micelles, ${ }^{18}$ polyvinyl alcohol (PVA), and poly(vinyl alcohol-co vinyl oleate) co-polymer, which was used to prepare micelles enhancing transcutaneous permeation of retinyl palmitate, have been proposed. ${ }^{19}$ PVA substituted with oleic acid has also been used for carrying lipophilic drugs. ${ }^{20}$

There are several examples of drug-loaded polymeric micelles for anticancer therapy being evaluated in preclinical studies with the aim of improving therapeutic efficacy. Micelle formulations being tested in clinical trials are summarized in Table 1.

Liposomes (diameter range 50-500 $\mathrm{nm}$ ) are structurally different from micelles for the presence of a bilayer membrane. Liposomes encapsulate a region of aqueous solution inside the membrane; hydrophilic solutes, that are not able to readily pass through the lipids, remain dissolved in the aqueous inner core. The formation is often driven by phosphatidylcholine enriched phospholipids. Since their discovery and introduction in the mid-1960s by Bangham and Horne, ${ }^{21}$ liposomes have been proposed as a shuttle to deliver a wide range of encapsulated hydrophilic drugs. Moreover, hydrophobic chemicals can also be loaded into the membrane, and in this way liposomes can carry both hydrophobic and 
Table I Micellar formulations being currently tested in clinical trials

\begin{tabular}{lllll}
\hline Polymeric micelle & Block copolymer & Drug & Indication & Clinical phase \\
\hline NK0I2 & PEG-PGlu(SN-38) & SN-38 & Breast cancer & II \\
NKI05 & PEG-P(aspartate) & Paclitaxel & Advanced stomach cancer & Adenocarcinoma of esophagus, \\
SPI049C & Pluronic L6I and FI27 & Doxorubicin & gastroesophageal junction and stomach & III \\
NC-6004 & PEG-PGlu(cisplatin) & Cisplatin & Solid tumors & I/II \\
Genexol-PM & PEG-P(D,L-lactide) & Paclitaxel & Breast cancer & IV \\
Genexol-PM & PEG-P(D,L-lactide) & Paclitaxel & Pancreatic cancer & II \\
Genexol-PM & PEG-P(D,L-lactide) & Paclitaxel & Non-small-cell lung cancer in & combination with carboplatin \\
Genexol-PM & PEG-P(D,L-lactide) & Paclitaxel & Pancreatic cancer in combination with & I/II \\
Genexol-PM & PEG-P(D,L-lactide) & Paclitaxel & Oemcitabine & Ovarian cancer in combination with \\
& & & carboplatin & I/II \\
\hline
\end{tabular}

Abbreviations: PEG, polyethylene glycol; SN38, 7-Ethyl-10-hydroxy-camptothecin.

hydrophilic drugs. In the last 20 years, a major development has been the formulation of polyethylene glycol (PEG) ylated liposomes (PEG-liposomes), known as stealth liposomes, with a prolonged circulation time in the blood. ${ }^{22}$ PEG-liposomes contain polyethylene glycol derivatives of phosphatidylethanolamine (PEG-lipid). The major difference compared to PEO is the molecular weight of the ethoxyl chain that is below 20,000 Daltons. Nowadays, eleven drugs with liposomal delivery systems have been approved by the US Food and Drug Administration (FDA) and six additional liposomal drugs are in advanced phase clinical trials. Two of these liposomal systems are employed in cancer therapy. The first stealth liposome was approved in 1995 by the US FDA and is still the only formulation to be approved (in the United States as DOXIL ${ }^{\circledR}$ [Alza Corporation, Vacaville, CA, USA] and in Europe as Caelyx ${ }^{\circledR}$ [Janssen Pharmaceutica, Beerse, Belgium]), for the treatment of Kaposi's sarcoma ${ }^{23}$ and recurrent ovarian cancer. ${ }^{24}$ DOXIL liposomes are approximately $100 \mathrm{~nm}$ in diameter with the following lipid composition (expressed as percentage mole ratio): hydrogenated soybean phosphatidylcholine (56.2\%), cholesterol (38.3\%), polyethylene-glycol (molecular weight [MW] 1,900) derivatized distearoyl-phosphatidylethanolamine (5.3\%), and $\alpha$-tocopherol $(0.2 \%)$. Loading of doxorubicin ( $0.125 \mathrm{drug} /$ lipid weight ratio) is based on the ammonium sulfate gradient method.

The combined use of drugs acting on different targets within cancer cells is widely utilized in oncology to improve efficacy, overcome undesirable toxicity, reduce the administered amounts of each agent, and reach multiple targets thereby increasing the therapeutic index of the native drugs. ${ }^{24}$ Supramolecular aggregates are theoretically capable of loading more than one drug at a time, which would allow for the simultaneous delivery of multiple drugs. ${ }^{25}$ Such an approach may be of additional value for clinical application of these delivery systems. Several examples of micelles and liposomes acting as co-delivery transporters are reported in the literature. ${ }^{26,27}$

Aside from the aforementioned aggregates generally belonging to the soft matter category, hard matter carriers, such as metal nanoparticles and ceramic nanoparticles, have been developed in recent years for their applications in diagnostics and therapeutics. ${ }^{28}$ One carefully studied metal nanoparticle is iron oxide, which can be used for such purposes after being coated with dextran, surfactants, phospholipids, or other compounds that increase its stability. Also, aminosilane-coated iron oxide nanoparticles have been utilized in thermotherapy to treat brain tumors. ${ }^{29}$

Magnetic nanoparticles (MNPs) of iron oxide possess unique magnetic properties and have the ability to function at the cellular and molecular level of biological interactions. Such nanoparticles are attractive for applications in thermotherapy, as contrast agents for magnetic resonance imaging (MRI) and as carriers for drug delivery. ${ }^{30}$ Other early nanotechnology approaches toward the chance of overcoming multidrug resistance (MDR) in cancer include covalent attachment of drug to polymers and solid-core nanoparticles to prevent drug efflux. ${ }^{31}$ Recently, DOX conjugated superparamagnetic iron oxide nanoparticles (SPION; NP-DOX) were developed and examined for susceptibility to MDR mediated drug efflux, a common mechanism of resistance to DOX..$^{32}$ Metal nanoparticles utilizing gold have good optical and chemical properties and are being investigated for use in infrared phototherapy applications. Ceramic nanoparticles such as silica, titania, and alumina are generally bioinert and have porous structures. These 
nanoparticles have also been proposed as drug delivery vehicles for cancer therapy. ${ }^{33}$

Nanoparticles have several features that make them appealing for these applications: a large surface area that allows them to trap an elevated number of active drug molecules; their structural versatility that allows them to obtain objects of varying sizes and pharmacokinetic properties in order to optimize drug delivery; and the possibility of coupling with other molecules, such as pharmacokinetic modifiers (PEG) or labels that can be used for tracking (magnetic, radioactive, or fluorescent).

\section{Active targeting}

The currently approved nanoparticle systems have, in some cases, improved the therapeutic index of approved drugs by reducing drug toxicity or enhancing drug efficacy. However, there are data indicating that PEGylated liposomes loaded with doxorubicin ${ }^{34}$ do not significantly improve therapeutic efficacy compared to the native carrier free drug. An explanation for these results may be that PEGylated liposomes only increase drug concentration in the tumor vasculature, but there is no significant change in the intracellular drug level, which is crucial for efficacy.

Therefore, active targeting is being actively pursued in order to target delivery. This approach is based on utilizing nanoparticles that have been externally modified with bioactive molecules capable of selectively recognizing targets present in cancer.

Different systems are used to provide targeting capabilities and these include monoclonal antibodies, receptorspecific peptides or proteins, nucleic acids (deoxyribonucleic acids/ribonucleic acids [DNA/RNA] aptamers), small molecules, and even vitamins or carbohydrates. Monoclonal antibodies or antibody fragments that can be selected with a high degree of specificity for the target tissue, with elevated binding affinities, are therefore particularly suitable for this task. Antibodies are being used to deliver radioisotopes, ${ }^{35}$ toxins, ${ }^{36}$ cytokines,${ }^{37}$ and other drugs. In certain settings the targeting antibody also displays therapeutic properties ${ }^{38}$ giving the added advantage of targeting the cancer cell by two distinct mechanisms. Despite the recent progress in antibody engineering, antibody development is still fairly expensive and use of such biomolecules as drugs presents stability and storage problems when designing formulations for clinical use. Another issue that may arise with non-humanized antibodies is immunogenicity, which may limit repeat administrations due to the risk of significant side effects.
On the other hand, several non-antibody ligands can be coupled to larger drug vectors for this same purpose. This class of compounds may display less selective interaction with potential targets. Ligands such as folate and transferrin, which target growth-factor receptors, ${ }^{39,40}$ have targets that are expressed not only in cancer cells but also in normal tissues. There are also physiological concentrations of native ligands that may compete for the target.

\section{Peptide targeting}

Natural and synthetic peptides are a class of small ligands that have great potential for such applications. They offer the advantage of providing infinite sequence/structure possibilities that can potentially be designed to bind to any cancer related target. Furthermore, such an approach is expected to yield fewer problems related to immunogenicity. Among potential targets, there are several cell surface receptor systems that have small peptides as ligands that have been shown to be highly expressed in a variety of neoplastic and non-neoplastic cells. ${ }^{41}$ Furthermore, receptor-targeting peptides have shown a high level of internalization within tumor cells via receptor-mediated endocytosis. Such a feature of these systems may be of value in facilitating intracellular delivery of the intended payload. The drawbacks related to the use of these compounds are the relatively lower target affinities and the metabolic instability of these compounds that may be extremely sensitive to protease degradation. Improving metabolic stability and pharmacokinetics can be attempted by modifying peptide sequences using specific coded or uncoded amino acids or amino acids with D configurations. Cycling of the N-terminal with the C-terminal or with a side-chain, or the C-terminal with a side-chain and the side-chain with another side-chain, can also be utilized for such purpose. Another advantage is the possibility of designing analogs that can act as antagonists. Cell surface receptor antagonists show the dual advantage of not activating the biological pathways following receptor binding and have also been shown to have higher binding capacities to their agonist counterparts. ${ }^{42,43}$ These attractive physical properties coupled with their smaller size make peptides very appealing candidates for developing new target-specific nanoparticles.

Most peptide based targeting ligands are derived from known endogenous proteins capable of binding the target receptor with high affinity. Molecular modeling of new peptide sequences based on the known three-dimensional structure of the target receptor is also a possible strategy for rational design of new compounds, although such an approach requires thorough knowledge of the structure of 
ligand/receptor interaction. ${ }^{44} \mathrm{~A}$ further possibility for identifying new peptide sequences for recognizing tumor-associated proteins is the use of phage display techniques. ${ }^{45}$

Once the binding sequence is identified a number of synthetic strategies have been put in place in order to modify the surface of micelles, liposomes, or nanoparticles in order to display the targeting peptide sequence. One main concern in this part of development is to achieve high coupling efficiency while distancing the bioactive peptide from the nanostructure surface in order to maintain the specific conformation required for high affinity binding to the target. The bioactive peptide may be introduced on the aggregate surface directly during nanostructure preparation by coupling the peptide to an amphiphilic moiety (pre-functionalization strategy; Figure 1A), or introducing the peptide on the surface of the nanostructures after they have been obtained (postfunctionalization; Figure 1B).

The first method, usually employed for the obtainment of peptide containing micelles and liposomes, needs a well-purified amphiphilic peptide molecule; it is mixed in appropriate solvents and in the chosen ratio with other amphiphilic molecules and phospholipids; then micelles or liposomes are obtained by evaporating the solvent or using extrusion procedures. The advantage of this approach is that one obtains a well-defined amount of bioactive molecules in the aggregates and there are no impurities. With

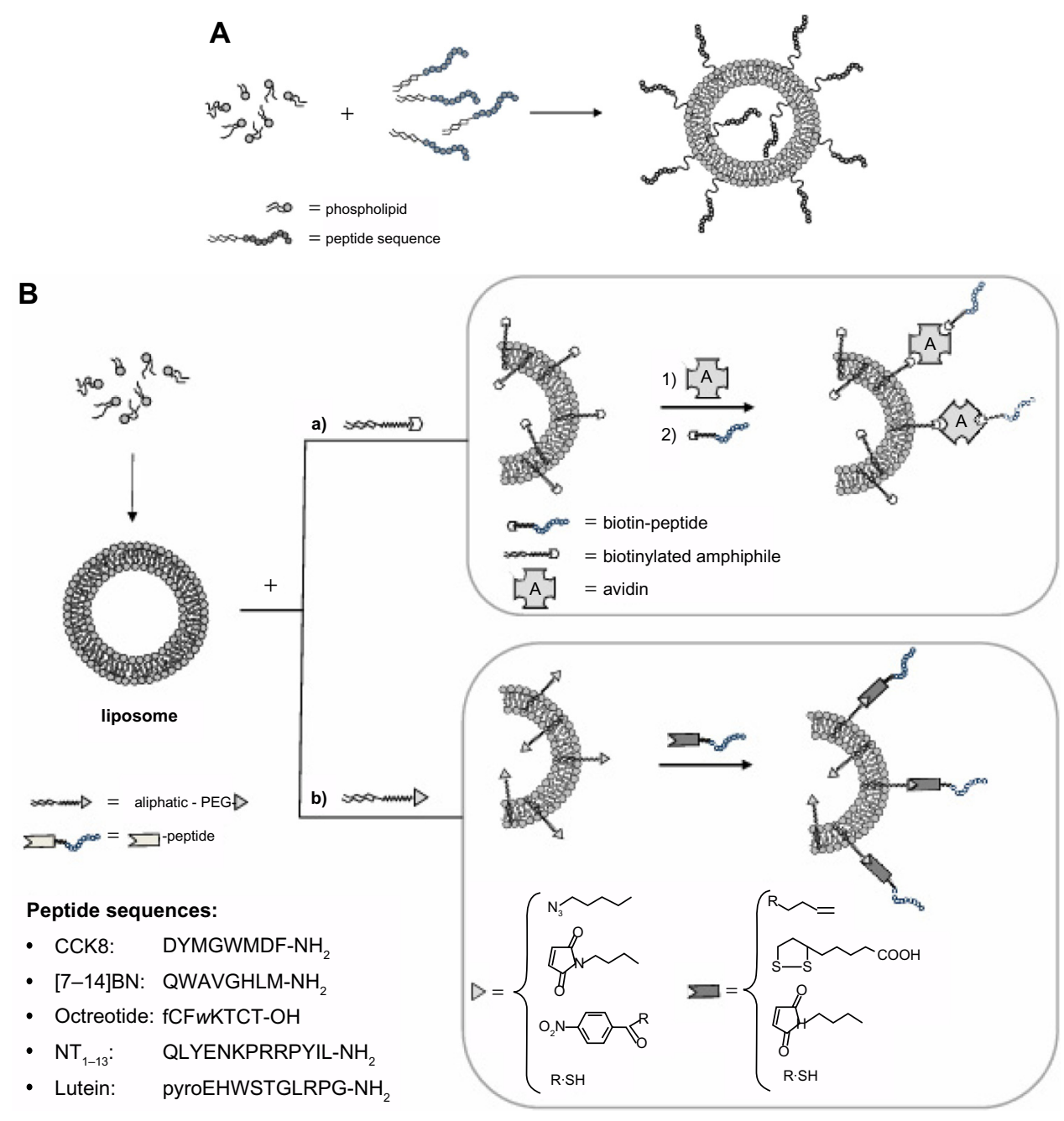

Figure I Introduction of bioactive peptides on aggregate surfaces.

Notes: (A) The bioactive peptide may be introduced on the aggregate surface directly during nanostructure preparation by coupling the peptide to an amphiphilic moiety according to a pre-functionalization strategy; with this approach, however, the bioactive peptide is displayed on the external liposome surface as well as in the inner compartment. (B) Alternatively, peptide introduction can be performed after nanostructures have been obtained, according to a post-functionalization strategy. For the second approach, peptide coupling after liposome or nanoparticle preparation involves the introduction of suitable activated functional groups onto the external side of liposomes or nanoparticles for covalent or non-covalent peptide binding. To guarantee correct orientation of the targeting ligand, biorthogonal and site-specific surface reactions are necessary. Functional groups commonly used are: I) amine for the amine-N-hydroxysuccinamide coupling method, 2) maleimide for Michael addition, 3) azide for $\mathrm{Cu}(\mathrm{l})$-catalized Huisgen cycloaddition (CuAAC), 4) biotin for non-covalent interaction with avidin or triphosphines for Staudinger ligation, and hydroxylamine for oxime bond. In the inset are reported the peptide sequences.

Abbreviations: BN, bombesin; CCK8, cholecystokinin-8; NT, neurotensin; PEG, polyethylene glycol. 
this approach, however, the bioactive peptide is displayed on the external liposome surface as well as in the inner compartment.

For the second approach, peptide coupling after liposome or nanoparticle preparation involves the introduction of suitable activated functional groups onto the external side of liposomes or nanoparticles for covalent or non-covalent peptide binding. To guarantee correct orientation of the targeting ligand, biorthogonal and site-specific surface reactions are necessary. The synthetic strategy should be aimed at optimizing reproducibility and yield of the coupling reaction. Functional groups commonly used are: a) amine for the amineN-Hydroxysuccinimide coupling method; b) maleimide for Michael addition; c) azide for $\mathrm{Cu}(\mathrm{I})$-catalyzed Huisgen cycloaddition (CuAAC); and d) biotin for non-covalent interaction with avidin or triphosphines for Staudinger ligation, and recently, hydroxylamine for oxime bond. ${ }^{46}$

A considerable number of molecular targets for peptides are either exclusively expressed or overexpressed on both cancer vasculature and cancer cells. They can be classified into three wide categories: integrins; growth factor receptors (GFRs); and G-protein coupled receptors (GPCRs). These receptors offer attractive targets for anticancer therapeutics as they are often implicated in tumor growth and progression. Many nanoparticles and liposomes have been labeled with peptides capable of interacting with these receptors and have been reported in the literature in the last decade. Nanoparticles grafted with the RGD sequence able to bind integrin receptors have been widely evaluated for the treatment of different cancers, such as ovarian cancer, melanoma, and breast carcinoma. ${ }^{47-49}$ Peptides targeting growth factor receptors have been utilized to functionalize liposomes encapsulating chemo-therapeutics. ${ }^{50}$ Peptides have also been developed to target the extracellular matrix of the diseased tissues, and this is an important alternative strategy to target unhealthy tissues which can also be incorporated with nanomedicine. ${ }^{51,52}$

This review will focus on delivery systems containing peptides that recognize GPCRs. GPCRs constitute a membrane protein family involved in the recognition and transduction of signals as diverse as light, $\mathrm{Ca}^{2+}$, and small molecule signaling, including peptides, nucleotides, and proteins. The general structural features, obtained by indirect studies as well as X-ray crystallography, indicate the presence of seven transmembrane helices connected by three intracellular and three extracellular loops. The N-terminal domain is directed into the extracellular space and C-terminal points to the intracellular space. Ligand binding to receptor is a crucial event in initiating signals, and the study of how ligands interact with their receptors can reveal the molecular basis for both binding and receptor activation. The ligand binding site for peptides has been found in the N-terminal extradomain or on the portion of the extracellular loops adjacent to the extracellular moiety of the transmembrane helices. Knowledge of the structural details of this interaction could be very useful for designing ligands for targeted delivery. Unfortunately, detailed structural characterization of the ligand-receptor complex for most systems is very difficult to obtain. However several approaches, such as biochemical affinity, photoaffinity labeling, ${ }^{53}$ and site-directed mutagenesis ${ }^{54}$ have allowed us to determine which amino acid residues are involved in binding. The interest in developing agonist or antagonist peptides against these receptors is based on the biological role these receptor pathways have in specific cancer types.

Overexpression of small peptide receptors has been documented for a wide number of cancers. ${ }^{41}$ As many as $10^{5}-10^{6}$ receptor molecules per cell or receptor densities in the $\mathrm{pmol} \cdot \mathrm{mg}^{-1}$ protein range have been reported for a variety of systems, such as somatostatin receptors in neuroendocrine tumors, cholecystokinin (CCK) receptors in medullary thyroid cancer, bombesin receptors in prostate and breast carcinoma, and several others.

We will review delivery systems targeting a family of regulatory peptide receptors overexpressed in specific cancer types, focusing particularly on receptors for somatostatin (SST), cholecystokinin (CCK), gastrin-releasing peptides (GRP/Bombesin), lutein, and neurotensin.

\section{Somatostatin based delivery systems}

At least five subtypes of somatostatin receptors (SSTRs; SSTRs 1-5) have been discovered: they belong to a distinct group within the superfamily of G-protein-coupled receptors. SST binds these receptors with high affinity, with the main physiologic purpose of inhibiting some functions of the target cell, for example blocking growth-hormone release in the hypothalamus. This endogenous peptide is preferentially produced in neurons and secretory cells in the central and peripheral nervous system and in the gastrointestinal tract. ${ }^{55}$ The different receptor subtypes show 50\% sequence homology, which is particularly evident in the transmembrane regions. Aside from the expression in normal tissues, SSTRs have been found in many different types of tumors, mostly of neuroendocrine origin, such as gastroenteropancreatic tumors, neuroblastomas, medulloblastomas, breast cancers, meningiomas, paragangliomas, renal cell carcinomas, 
lymphomas, hepatocellular carcinomas, and small cell lung cancers. In general, SSTR2 is the most common SSTR subtype found in human tumors, followed by SSTR1, with SSTR3, 4 and 5 being less common. The high frequency of SSTR expression in human tumors has been exploited for diagnostic and therapeutic applications.

The wild type SST tetradecapeptide has a limited therapeutic value due to its short biological half-life ( $<3$ minutes). ${ }^{55}$ This feature pressed scientists to develop peptide analogs with improved stability to enzymatic cleavage and therefore with prolonged circulation time. The most successful derivative is octreotide (OCT).$^{56}$ This eight amino acid analog, developed by Sandoz (now Novartis) is able to induce endocytosis by binding to SSTR2 with high affinity (inhibitory concentration $\left.[\mathrm{IC}]_{50}=2 \mathrm{nM}\right)$, and SSTR $3\left(\mathrm{IC}_{50}=376 \mathrm{nM}\right)$ and SSTR $5\left(\mathrm{IC}_{50}=299 \mathrm{nM}\right)$ to lesser degrees. OCT has been a subject of extensive structural studies, including nuclear magnetic resonance (NMR), ${ }^{57}$ in order to design peptide conjugates as vehicles for contrast agents or drugs. OCT peptide binding to receptors is not affected when chemical modifications are introduced on its N-terminus. Radiolabeled OCT conjugates are commonly used in clinical tumor diagnosis ${ }^{58}$ and in clinical trials for peptide receptor radiotherapy (PRRT).$^{59}$ OCT has been further used to enhance the delivery of drugs to tumor cells by chemically conjugating it with anti-tumor drugs. ${ }^{60}$ These promising results prompted many researchers to develop OCT as a specific targeting moiety to deliver nanocarriers incorporating anti-tumor drugs into tumor cells via SSTRs endocytosis (Table 2).

\section{Liposomes and micelles}

One of the most relevant issues for chemotherapeutic drugs is poor solubility in water and/or in buffers, which limits the quantities of drug that can be administered. Supramolecular aggregates can improve the biodistribution and pharmacokinetics of these drugs. ${ }^{8}$ Moreover, as previously reported, severe side effects of these drugs can be reduced by enhancing delivery to the target tissue. ${ }^{13}$ In the last few years, many different aggregates have been developed to carry chemotherapeutic drugs to SSTR2 expressing tumors by coupling to the OCT peptide. ${ }^{61}$

Octreotide labeled aggregates may be obtained following the two approaches presented above. One strategy was based on synthesizing the OCT on trityl resin in solid phase and coupling the other molecular building blocks step by step. The advantage of this approach is to supervise all synthetic steps protecting all reactive functions in order to avoid collateral products. The most relevant disadvantage is the difficulty in

Table 2 Octreotide labeled supramolecular aggregates or nanoparticles

\begin{tabular}{|c|c|c|c|}
\hline Peptide conjugation methods & Formulation & Drug or nanoparticles & References \\
\hline OCT versus NHS-PEG-b-PCL & Micelle: OCT-PEG-b-PCL & PTX-salinomycin & 65 \\
\hline OCT versus $\mathrm{p}$-nitrophenylcarbonyl- & NLC: OCT-polyethylene glycol(100) & HCPT & 67 \\
\hline PEG $(100)$ monostearate & monostearate (PGMS) & & \\
\hline OCT versus $p$-nitrophenylcarbonyl- & NLC: OCT-polyethylene glycol(I00) & HCPT & 68 \\
\hline PEG $(100)$ monostearate & monostearate (PGMS) & & \\
\hline $\mathrm{OCT}^{-P E G_{3400}}$-DSPE & $\begin{array}{l}\text { Liposome: DSPC OCT-PEG } 3400 \text {-DSPE } \\
\text { (different ratio) }\end{array}$ & Irinotecan CPT II & 70 \\
\hline OCT versus BocNHPEG-NHS & $\begin{array}{l}\text { Micelle OCT(Phe)-PEG-SA (OPS)/ } \\
\text { (OCC) (in different ratio) }\end{array}$ & DOX & 73 \\
\hline OCT versus BocNHPEG-NHS & $\begin{array}{l}\text { Micelles (OCT(Phe)-PEG-DOCA) } \\
\text { (DAHC) I:5 (molar ratio) }\end{array}$ & DOX & 74 \\
\hline OCT versus $\mathrm{PNP}-\mathrm{PEG}-\mathrm{PE}$ & $\begin{array}{l}\text { Liposome PC:Chol:OCT-PEG-PE } \\
\text { 5:1:0.5 (molar ratio) }\end{array}$ & DOX & 75 \\
\hline OCT versus DSPE-PEG-NHS & $\begin{array}{l}\text { Liposome EPC/chol/ } \\
\text { DSPE-PEG/DSPE-PEG-OCT } \\
(\text { I5.9:4.1:5.7:0.3, w/w) }\end{array}$ & DOX & 76 \\
\hline OCT amphiphilc solid phase synthesis & $\begin{array}{l}\text { Liposome }(\mathrm{Cl} 8)_{2}(\mathrm{AdOO})_{5} \mathrm{OCT} / \\
\text { Peg }_{1500} \mathrm{Lys}_{(\mathrm{Pt} \text {-aminoEtGly }) \text { - } \mathrm{Lys}(\mathrm{Cl} 8)_{2}} \\
\text { I:9 (molar ratio) }\end{array}$ & $\mathrm{Pt}(\mathrm{II}), \mathrm{DOX}$ & 77 \\
\hline DSPE-PEG2000-OCT (not declared) & $\begin{array}{l}\text { Liposome } \\
\text { EPC/Chol/DSPE-PEG-OCT/CA- } \\
4 ; 25: 1.28: 6: 2, w / w\end{array}$ & CA-4 and DOX & 78 \\
\hline TOC-Boc AuNPs & & AuNPs & 80 \\
\hline Octreotide versus AuNPs $(\sim 20 \mathrm{~nm})$ & & AuNPs & 81 \\
\hline
\end{tabular}

Abbreviations: AuNP, gold nanoparticles; Boc, tert-Butyl carbamates; DOX, doxorubicin; HCPT, I0-hydroxycamptothecin; NHS, succinimidyl carboxymethyl ester; OCT, octreotide; PEG, polyethylene glycol; PTX, paclitaxel; TOC, Tyr3-octreotide. 
purifying these molecules that are poorly soluble and which need to be solubilized in organic solvents, as they would aggregate in water-based buffers. An alternative strategy consists in assembling the amphiphilic molecule in solution. The hydrophobic moiety and the hydrophilic linker are coupled on the N-terminus of the OCT after peptide purification. In this case side reactions are of concern as OCT has two primary amino groups (the N-terminus and the side chain of Lys) and the coupling reaction may get mono- or di-substituted derivatives. To limit the undesired products, reactions must be conducted at a $\mathrm{pH}$ value below 10 . In certain instances a test of $\alpha$ Lys-C digestion is necessary to further confirm the coupling site. Trypsin cleaves peptide chains mainly at the carboxyl side of lysine or arginine, except when either is followed by proline. If the conjugation occurs at the Lys residue, there would be no change in the mass spectrum after trypsinization; otherwise the modification occurring at the N-terminus would exhibit a reduced mass fragment. The OCT amphiphilic molecules can self-assemble, or generate micelles or liposomes by mixing with a surfactant. Hydrophobic drugs are preferentially loaded in the core of micelles, ${ }^{8}$ whereas water soluble drugs could be carried in the inner compartment of liposomes or in the hydrophilic shell of micelles.

Important issues in the development of OCT coupled aggregates are confirming that there is adequate exposure on the aggregate surface, and also confirming the ability of the OCT peptides in recognizing and binding the target receptor. In order to characterize these aggregates for their suitability for in vivo use as selective targeting tools, it is possible to study peptide properties on the aggregate surface through classical chemical physical methods. Morisco et $\mathrm{al}^{61}$ developed OCT containing aggregates for use as drug carriers and magnetic resonance imaging (MRI) contrast agents. The monomers, synthesized on solid phase, contain, in the same molecule, three different functions: the chelating agent (DTPAGlu or DOTA); OCT; and a hydrophobic moiety based on two C18 hydrophobic chains. These monomers (OCA-DTPAGlu, OCADOTA) self-assemble in water solution, giving stable micelles. Fluorescence studies indicate, for the two compounds as well as for their gadolinium complexes (OCA-DOTA[Gd] and OCA-DTPAGlu[Gd]), the complete exposure of OCT on the micelle surface. In fact, the tryptophan emission at 345-350 nm suggests a hydrophilic environment for this residue. Circular dichroism measurements show the predominant presence of an antiparallel beta-sheet peptide conformation characterized by a beta-like turn. This conformation has been demonstrated to be suitable for receptor binding.
The same group has also studied ${ }^{62}$ mixed aggregates formulated by co-assembling: a first monomer containing the OCT peptide, an ethoxyl spacer bound to the peptide N-terminus, and the hydrophobic moiety; a second monomer containing the same hydrophobic chains bound through a lysine residue to different polyamino-polycarboxy ligands; and a chelating agent such as DTPAGlu, DTPA, or DOTA to allow coordination of metal ions. Structural characterization of the aggregates indicates a shape and size of the supramolecular aggregates suitable for in vivo use. For these aggregates, fluorescent emission of the tryptophan residue at $340 \mathrm{~nm}$ also suggests exposure of the peptide to the water environment, thus available to interact with the SSTR2.

Later work by the group of Helbok et a ${ }^{63}$ demonstrated the in vitro and in vivo selective aggregate binding of OCT coupled PEGylated liposomal nanoparticles radiolabeled with indium-111. The OCT derivative was synthesized by cross-linking of the S-acetyl-mercaptopropionic acid peptide with Mal-DSPE-PEG2000. Liposomes were obtained by mixing the OCT derivative with adequate amounts of palmitoyl oleoyl-phosphatidylcholine (POPC), lyso-stearyl-phosphatidylglycerol (Lyso-PG), distearylphosphatidylcholine-polyethyleneglycol-2000 (DSPEPEG2000), and dimyristoyl phosphoethanolamine-DTPA (DMPE-DTPA) in a molar ratio of $0.1: 11: 7.5: 0.9: 2$, respectively. Targeting properties of the OCT labeled liposomes were evaluated in vitro on rat pancreatic tumor cells (AR42J), demonstrating specific binding and $\mathrm{IC}_{50}$ values in the low nanomolar range. Unfortunately only moderate uptake was observed when in vivo experiments were performed in animals; this may be explained by the limited and slow accessibility of target receptors on tumor cells by large constructs such as these, compared to small peptides that show much more rapid diffusion and binding to the receptors and cellular internalization.

Similar proof of concept was reported by Petersen et al. ${ }^{64}$ Liposomes (DSPC/Chol/DSPE-PEG2000/DSPE-PEG2000TATE in a molar ratio 50:40:9:1, respectively) with an encapsulated positron emitter ${ }^{64} \mathrm{Cu}$ for positron emission tomography (PET) imaging were tested in vivo in a mouse model. [Tyr3]-octreotate (TATE), an OCT analog, functionalized with maleimide, was covalently attached to the distal end of DSPE-PEG2000 via a thioether bond. Biodistribution and pharmacokinetic properties of TATE coupled liposomes were compared with peptide free liposomes and with the radiolabeled peptide alone. ${ }^{64} \mathrm{Cu}$-loaded PEGylated liposomes derivatized with the TATE peptide displayed significantly higher tumor-to-muscle (T/M) ratio (12.7 \pm 1.0$)$ compared 
to control-liposomes without TATE $(8.9 \pm 0.9)$ and to ${ }^{64} \mathrm{Cu}-$ DOTA-TATE peptide (7.2 \pm 0.3$)$. These results demonstrate the feasibility of utilizing somatostatin analogs for specific targeting of the above described aggregates to tumors overexpressing somatostatin receptors.

Paclitaxel (PTX) is a mitotic inhibitor used to treat patients with lung, ovarian, breast, head and neck cancers, and advanced forms of Kaposi's sarcoma. This drug is poorly soluble in water and thus is a suitable candidate for loading in micelles. Zhang et al studied a combination of PTX and salinomycin (SAL), an experimental drug recently found to be very effective on breast cancer stem cells. ${ }^{65}$ Both drugs were loaded in polyethylene glycol-b-polycaprolactone (PEG-bPCL) polymeric micelles obtaining OCT-(PTX)-PEG-b-PCL (OCT-M-PTX) and salinomycin (SAL)-loaded PEG-b-PCL (M-SAL). OCT was coupled to NHS-PEG-b-PCL through the activated NHS group in dimethyl sulfoxide (DMSO) solution. The prepared micelles have a diameter of approximately 25-30 nm, and the encapsulation efficiency of the drug was $>90 \%$. The presence of the OCT peptide favors uptake of micelles in SSTR overexpressing MCF-7 breast cancer cells. Moreover, free OCT can inhibit such interaction confirming that cellular uptake is indeed occurring by a receptormediated mechanism. The efficacy of combination therapy using OCT-M-PTX plus M-SAL was confirmed in vitro and in MCF-7 xenografts in mice: the combination treatment results in a stronger inhibitory effect on tumor survival by killing both non-stem cancer cells and cancer stem cells.

Another water insoluble chemotherapeutic in a broad spectrum of cancers, including leukemias and cancers of the liver, stomach, breast, and colon, is a natural derivative of camptothecin, the 10-hydroxycamptothecin (HCPT) in lactone form. One way to improve the solubility of HCPT is to change the lactone form to the carboxylate form by adding $\mathrm{NaOH}$. However, this leads to less activity and more unwanted toxicity. ${ }^{66}$ At the same time, HCPT has a short half-life in vivo and poor biodistribution. Obviously, pharmacokinetics of this molecule is improved by using drug carriers. Su et al ${ }^{67}$ formulated HCPT-loaded nanostructured lipid carriers (NLC) made from poly(ethylene glycol)-poly $(\gamma$-benzyl-L-glutamate) (PEG-PBLG). At this amphiphilic polymer the conjugate OCT labeled polyethylene glycol monostearate (OPMS) was added. The labeling procedure was carried out in a solution of p-nitrophenyl-PMS adding OCT and incubating at pH 9. The OCT binding on PMS was determined by bicinchoninic assay (BCA) protein assay kit. Nanoparticle size depends on the different molar ratio of their components. In a more recent study, the authors demonstrated that surface density of the targeting moiety was crucial to determine physicochemical properties, drug release, cellular uptake, and cytotoxicity.

Compared to pharmacokinetic studies, modified NLCs had a longer circulation than NLC due to PEGylation effect, and OPMS-modified NLCs had larger mean residence time than PGMS-modified NLCs, showing $58.5 \mathrm{ng} / \mathrm{mL}$ at 24 hours of drugs versus $15.8 \mathrm{ng} / \mathrm{mL}$. Furthermore, qualitative observation of cellular uptake by florescence microscopy showed higher uptake of OCT-modified NLCs on tumor cells (SMMC-7721) overexpressing somatostatin receptors, in comparison to OCT-modified NLCs uptake on control cells after incubation at $37^{\circ} \mathrm{C}$ for 2 hours. ${ }^{68}$

Irinotecan (CPT-11), another analog of camptothecin, induces a growth inhibition of tumor cells in medullary thyroid carcinoma (MTC). ${ }^{69}$ This derivative is water soluble but its use is limited because of many side effects. Iwase and Maitani $^{70}$ overcame these problems by loading this drug in OCT decorated liposomes. Liposomes were formulated by mixing DSPC lipids with OCT-PEG ${ }_{3400}$-DSPE amphiphilic molecules in different ratios. The association of modified OCT-targeted liposomes with TT cells was significantly higher than non-targeted PEGylated liposomes and was significantly inhibited by empty OCT-targeted liposomes but not by free OCT. The authors suggest that the affinity of free OCT and OCT-CL to SSTR are not the same. ${ }^{70}$ After 96 hours of exposure, cytotoxicity of OCT-targeted liposomal CPT-11 $\left(\mathrm{IC}_{50}: 1.05 \mu \mathrm{M}\right)$ was higher than free CPT-11 $\left(\mathrm{IC}_{50}: 3.76 \mu \mathrm{M}\right)$ or PEGylated liposomal CPT-11 $\left(\mathrm{IC}_{50}: 3.05 \mu \mathrm{M}\right)$. Moreover, OCT-targeted liposomal CPT-11 led to significantly higher antitumor activity and prolonged survival time compared with non-targeted liposomal and free CPT-11.

The major efforts in target delivery mediated by somatostatin analogs have been devoted to carry DOX on tumor cells. DOX is a hydrophilic drug and can be loaded in micelles or in liposome inner compartments. The approval of DOXIL in 1995 opened a route to new formulations in order to improve efficacy and tolerability of the drug as compared with the non-liposomal counterparts or passive targeting aggregates.

Hydrophobilized polysaccharides polymeric micelles are currently very attractive for researchers due to their well-known nontoxicity and excellent biocompatibility and biodegradability. ${ }^{71}$ In the last few years, Zou et al ${ }^{72}$ studied N-octyl-O,N-carboxymethyl chitosan (OCC) and $\mathrm{N}$-deoxycholic acid-O,N-hydroxyethylation chitosan (DAHC) micelles. OCC and DAHC micelles exhibited good loading capacities for DOX, with a drug loading content (DLC) in the $22 \%-30 \%$ range. The first attempt to graft them 
with OCT was carried out, conjugating the N-terminal moiety to the free carboxylic groups of OCT. ${ }^{72}$ The reaction had an extremely low (about 3\%) yield, which is largely due to the high molecular weights of OCT and chitosan derivatives, the strong hydrogen bonds in the chitosan backbone, and poor solubility of chitosan derivatives in organic solvent. This result pushed toward alternative mixed aggregates, adding to DAHC a ligand-PEG-lipid conjugate able to guarantee same time long circulation time in blood and ligand targeting. Therefore the peptide N-terminal function was anchored in solution to a PEG fragment and this moiety was conjugated to an aliphatic chain obtaining the OCT(Phe)-PEG-SA (OPS) monomer or to deoxycholic acid obtaining the OCT(Phe)PEG-DOCA (OPD). ${ }^{73}$

Micelles formulated by adding OPS to the final formulation were not significantly affected with respect to size or shape. Their diameter is less than $120 \mathrm{~nm}$ with spherical shape and zeta potential of $30 \mathrm{mV}$. Enhanced tumor-targeting capacity was observed in BALB/c nude mice bearing MCF-7 cancer xenografts as compared with the self-assembling OCC micelles. Moreover, pharmacodynamic studies demonstrated that DOX-OCC-OCT presented a stronger inhibition of tumor growth (86.7\% versus $33.3 \%)$ and lower systemic toxicity compared to free DOX and DOX-OCC micelles.

Insertion of OPD in aggregate formulations showed no significant effect on drug loading properties while slightly increasing particle size (230 $\mathrm{nm}$ average diameter versus $200 \mathrm{~nm}$ ) and partly shielded the positive charges on the surface of micelles. ${ }^{7}$ Accelerated release rate of DOX from micelles were also observed after OPD modification, the release profile also exhibited $\mathrm{pH}$-sensitive properties. Compared to DAHC-DOX micelles, OPD-DAHC-DOX micelles exhibited significantly stronger cytotoxicity to human breast cancer cells (MCF-7; SSTRs overexpression) but had almost the same effect on human embryonic lung fibroblasts (WI-38 cells; no SSTRs expression). The results of flow cytometry and confocal laser scanning microscopy further revealed that OPD-DAHC-DOX micelles could be selectively taken into tumor cells by SSTRs-mediated endocytosis. In vivo investigation on nude mice confirmed that OPD-DAHC micelles possessed much higher tumor-targeting capacity than the DAHC control and exhibited enhanced anti-tumor efficacy and decreased systemic toxicity. Figure 2 shows images of micelles in the tumor-bearing mice at 1 , 6,12 , and 24 hours after administration of fluorescent dye, Cyanine 7, encapsulated into DAHC (Figure 2A) micelles and OPD (20\%)-DAHC micelles (Figure 2B). During the live imaging test, most of the $\mathrm{Cy} 7$ accumulated in liver and tumor

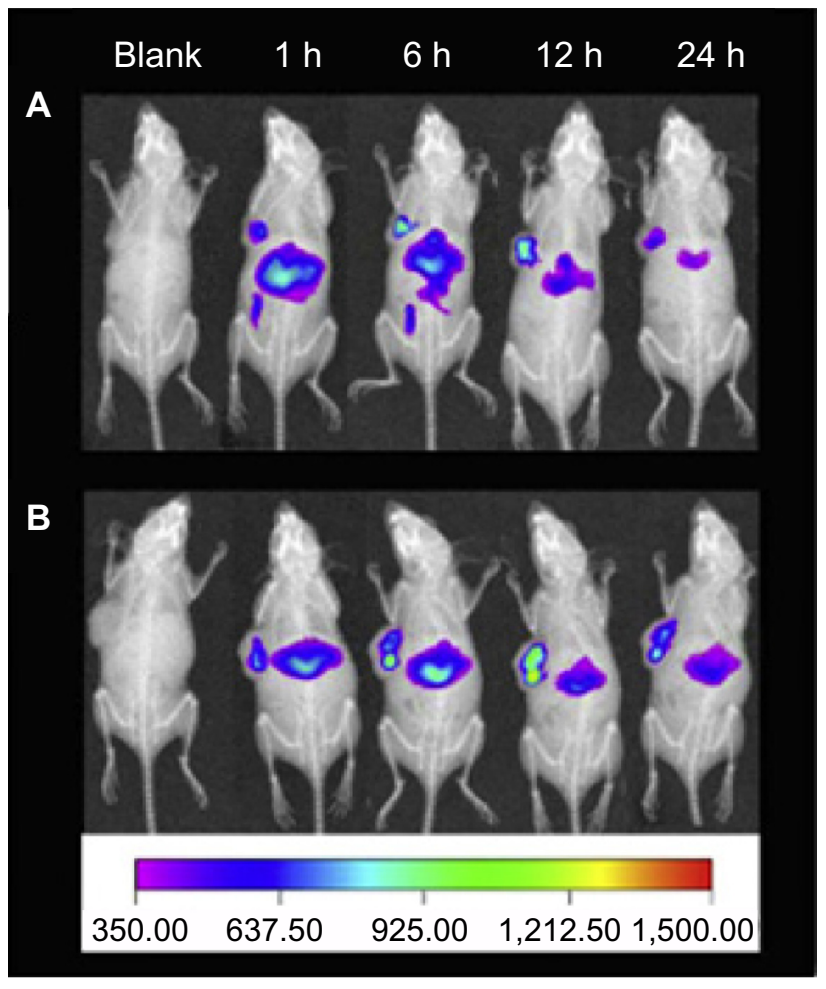

Figure 2 In vivo imaging of tumor-bearing mice after administration of $\mathrm{Cy}-7$ loaded DAHC micelles (A) and Cy-7 loaded OPD(20\%)-DAHC micelles (B) at I, 6, I2, and 24 hours.

Note: Reprinted from Biomaterials, 33(27), Huo M, Zou A, Yao C, et al, Somatostatin receptor-mediated tumor-targeting drug delivery using octreotide-PEG-deoxycholic acid conjugate-modified $\mathrm{N}$-deoxycholic acid-O, N-hydroxyethylation chitosan micelles, 6393-6407, Copyright (2012) with permission from Elsevier. ${ }^{74}$

Abbreviations: DAHC, N-deoxycholic acid-O,N-hydroxyethylation chitosan; OPD, OCT(Phe)-PEG-DOCA; h, hours.

after intravenous administration of both micellar formulations. However, preferential accumulation of fluorescence was obvious in the tumor site compared to the liver or other normal tissues at 12 and 24 hours after injection. Moreover, the OPD-DAHC micelles showed higher tumor-targeting efficiency, which led to higher accumulation of micelles in the tumors than DAHC micelles. These results provide decisive evidence that the designed OPD-DAHC micelles are suitable for tumor-specific drug delivery. This high tumor targetability of micelles might be due to a combination of an EPR effect and receptor-mediated uptake of micelles (Figure 2).

OCT-polyethylene glycol-phosphatidylethanolamine (OCTPEG-PE) was developed for the assembling of liposomes; the effect of OCT modification on the enhancement of the delivery and targeting of DOX-loaded liposomes was investigated in vitro and in vivo. ${ }^{75}$ OCT-PEG-PE was synthesized by a threestep reaction. DOX loading was carried out by the well assessed ammonium sulfate gradient method. Both drug uptake assays and cell apoptosis assays suggested that octreotide-labeled liposome (DOX-OL) noticeably increased the uptake of DOX by 
fluorescent measurement (about 100\% higher than that in unlabeled liposome [DOX-CL] cases) in SMMC-7721 cells and showed a more significant cytotoxicity compared to DOX-CL. The effect of DOX-OL was remarkably inhibited by free OCT. In contrast, no significant difference in drug cytotoxicity was found between DOX-OL and DOX-CL in CHO cells without obvious expression of SSTRs. The study of ex vivo fluorescence tissues imaging of BALB/c mice and in vivo tissue distribution of B16 tumor-bearing mice indicated that DOX-OL caused remarkable accumulation of DOX in melanoma tumors and the pancreas, in which the SSTRs are highly expressed. In another study, ${ }^{76}$ DOX-loaded OCT-DSPE-PEG monomer containing sterically stabilized liposomes (SSL) increased intracellular delivery of DOX in SSTR2-positive cells, through a mechanism of receptor-mediated endocytosis, as demonstrated by fluorescence spectrophotometry, confocal laser scanning microscopy, and flow cytometry studies. Confocal microscopy studies were carried out on NCI-H446, MCF-7, and Chinese hamster ovary (CHO) cells. After 3 hours of incubation with SSL-DOX, OCTSSL-DOX, or free DOX at DOX concentration of $10 \mu \mathrm{M}$ at $37^{\circ} \mathrm{C}$, NCI-H446 and MCF-7 displayed more red fluorescence of DOX than SSL-DOX ones. In terms of $\mathrm{CHO}$, there was no red fluorescence in both passive and active targeting liposome groups, proving no expression of SSTR2 on the cells. The active targeting was confirmed by treating with excess free OCT ( 5 $\mathrm{mg} / \mathrm{mL}$ ). In this case, the uptake of OCT-SSL-DOX by NCI$\mathrm{H} 446$ cells at $37^{\circ} \mathrm{C}$ was significantly inhibited because of the preoccupation of receptors.

Compared to SSL, OCT modification on SSL exhibited little effect on the physicochemical properties of SSL. However, it reduced the circulation time of loaded-DOX to some extent in rats, increased cytotoxicity in SSTR2-positive tumor cells, enhanced drug accumulation in tumor tissue, and improved anticancer efficacy in SSTR2-overexpressing tumor model. The antitumor effect in vivo of OCT-SSL-DOX was demonstrated inhibiting tumor growth better than that of SSL-DOX $(P<0.05)$.

Cis platinum is frequently used in combination with other drugs such as PTX, bleomycin, vinblastine, and in several trials with DOX.

As proof of concept of combined therapy based on DOX and platinum complexes, OCT grafted liposomal aggregates were recently formulated and studied. ${ }^{77}$ Mixed aggregates were formulated by co-assembling, at a 10:90 molar ratio, a first monomer containing two $\mathrm{C} 18$ hydrophobic moieties bound to the N-terminus of the cyclic OCT peptide, and spaced from the bioactive peptide by five units of dioxoethylene linkers, $(\mathrm{C} 18)_{2}(\mathrm{AdOO})_{5}-\mathrm{OCT}$, and a second amphiphilic monomer containing a platinum complex anchored to the lipophilic tail, (C18) 2 PKAG-Pt. Mixed aggregates (C18) 2 -PKAG-Pt/ $(\mathrm{C} 18)_{2}(\mathrm{AdOO})_{5}$-OCT give large liposomes with a diameter of $168 \mathrm{~nm}$. DOX encapsulation in the inner compartment was obtained by using the $\mathrm{pH}$ gradient method.

Another example of combined therapy was the use, at the same time, of DOX and combretastatin. Combretastatin A-4, the principal cancer cell growth-inhibitory constituent of the Zulu medicinal plant Combretum caffrum, has been undergoing preclinical development. ${ }^{78}$ However, the very limited water solubility of this phenol has complicated drug formation. Loading in aggregates could be an important improvement for its use. Both combretastatin A-4 (CA-4) and DOX were loaded in OCT-modified stealth liposomes in order to achieve the active delivery of these two drugs, followed by sequentially suppressing tumor vasculature and tumor cells. The drug loading efficiency of DOX was consistently greater than $95 \%$, while it was $70 \%-80 \%$ for CA-4. The drug encapsulation efficiency in liposomes was not affected by OCT modification. A rapid release of CA-4 followed by a slow release of DOX was observed in vitro. In fact, the release of CA-4 was more than $60 \%$ at 8 hours, while DOX released less than $20 \%$ at 48 hours. The active targeted liposomes OCT-L[CD] showed a specific cellular uptake through ligand-receptor interaction and a higher antitumor effect in vitro against SSTR positive cell line. The in vivo sequential killing effect of such systems was found as evidenced by the fast inhibition of blood vessels and slow apoptosis-inducing of tumor cells. The anticancer efficacy of different formulations is displayed in Figure 3. As seen in Figure $3 \mathrm{~A}$, the tumor volume was always the smallest at each test point in OCT-L[CD] group, suggesting its stronger inhibition effect on solid tumor compared to other groups $(P<0.05)$. The excised tumors in OCT-L[CD] group were also the smallest at the end of the test (Figure 3B). The results were in accordance with the antitumor study and cell uptake in vitro.

\section{Metal nanoparticles}

Metal nanoparticles have been extensively studied and offer extraordinary features for diagnostic as well as therapeutic applications. ${ }^{79}$ Multifunctional systems of gold nanoparticles (AuNPs) capped by the [Tyr3]Octreotide (TOC) peptide were prepared and characterized by transmission electron microscopy (TEM) and UV-Vis (ultraviolet-visible), infrared, and fluorescence spectroscopy. ${ }^{80}$ AuNPs and AuNP-TOC fluorescence emission spectra were obtained both in solution and in murine AR42J-tumor tissues. Results suggest that AuNP were functionalized with TOC through interactions with the $\mathrm{N}$-terminal amine function of the 


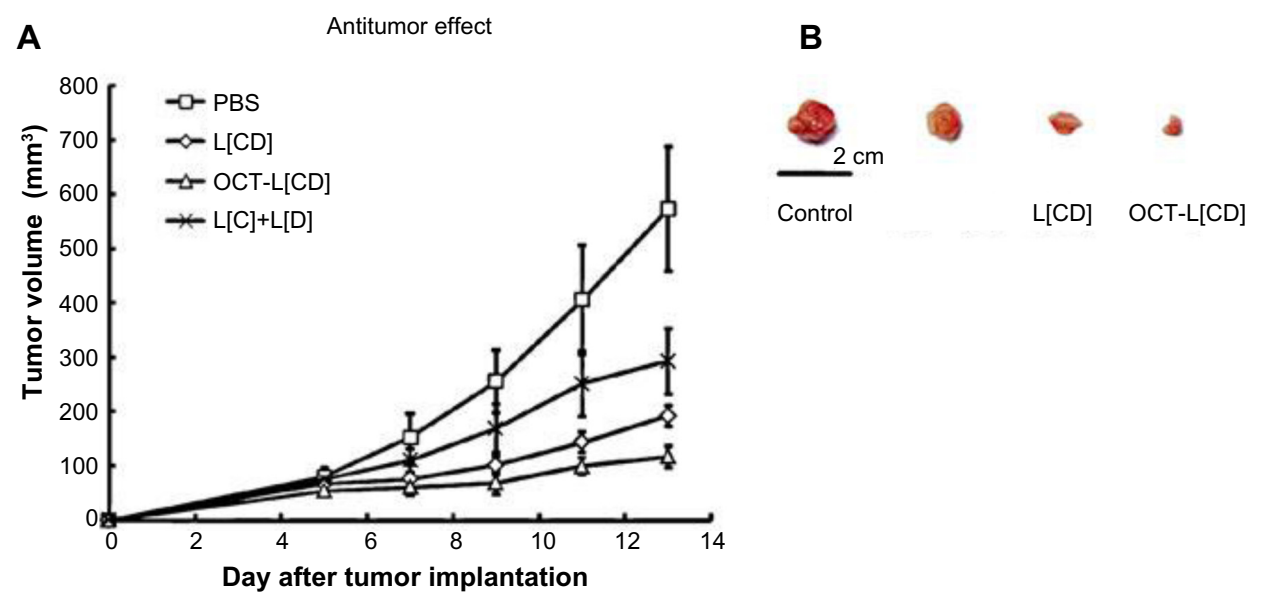

Figure 3 Antitumor efficiency of different treatments in MCF-7-bearing subcutaneous tumor models in nude mice. (A) Tumor volumes versus time. Data represent mean \pm standard deviation $(n=6)$. (B) Tumors excised at the end of the tests.

Note: Springer and Pharm Res, 29, 20I2, 2902-29II, Spatiotemporally controlled co-delivery of anti-vasculature agent and cytotoxic drug by octreotide-modified stealth liposomes, Dai W, Jin W, Zhang J, et al, Figure 10. ${ }^{78}$ With kind permission from Springer Science and Business Media.

Abbreviations: PBS, phosphate buffer solution; OCT, octreotide.

phenylalanine, the amide groups, and possibly with the indole group of the tryptophan residue. The fluorescence analyses in tissue revealed a recognition of the AuNP-TOC conjugate for the neuroendocrine tumor because of the lower energy position of the fluorescence resonance $(692$ $\mathrm{nm})$ with respect to that of the AuNP in the same tumoral tissue $(684 \mathrm{~nm})$. The emission band observed in the near infrared region (692 nm) opens, for AuNP-TOC, a potential use as theranostics.

The effect of laser heating, a well-characterized AuNPOCT system on HeLa cell viability, was evaluated as a suitable agent for plasmonic photothermal therapy in the treatment of cervical cancer. ${ }^{81}$ The peptide was conjugated to AuNPs $(\sim 20 \mathrm{~nm})$ by spontaneous reaction of thiol groups. HeLa cells were incubated at $37^{\circ} \mathrm{C}$ with AuNP-citrate, with AuNP-OCT, or without nanoparticles. After laser irradiation, the presence of AuNP caused a significant increase in the temperature of the medium $\left(48^{\circ} \mathrm{C}\right.$ versus $38.3^{\circ} \mathrm{C}$ without AuNP). The AuNP-OCT system resulted in a significant decrease in cell viability of up to $6 \%$ compared to the AuNP-citrate system $(15.8 \% \pm 2.1 \%)$. Two possible mechanisms could be at play: 1) OCT alone exerts an effect on survival HeLa cells, or 2) the release of heat $\left(-727^{\circ} \mathrm{C}\right.$ per nanoparticle $)$ in the membranes or cytoplasm of the cells caused by the interaction between AuNP-OCT and somatostatin receptors reduced viability.

\section{Cholecystokinin based delivery systems}

The gastrointestinal peptides gastrin and cholecystokinin (CCK) exist in different molecular forms of variable length with the same five terminal amino acid sequences at their carboxyl termini. They act as neurotransmitters in the brain and as regulators of various functions of the gastrointestinal tract, primarily at the level of the stomach, pancreas, and gallbladder. ${ }^{82} \mathrm{CCK}$ and gastrin actions are mediated by several receptor subtypes, the best characterized being CCK1 and CCK2 receptors. ${ }^{83}$ The overexpression of either or both subtypes of these receptors has been found in certain human tumors and particularly in tumors of neuroendocrine origin. In particular, CCK2-R is overexpressed in a large percentage $(90 \%)$ of medullary thyroid cancers, and to a lesser level in small cell lung cancers and in gastroenteropancreatic (GEP) tumors. Development of CCK2-R targeting radiopharmaceuticals for imaging and for radionuclide therapy has gained great interest. A wide number of CCK and gastrin derivatives displaying high affinity for the CCK2-R have been characterized over the past years for the purpose of in vivo receptor targeting for imaging and for therapy. ${ }^{84}$ In all derivatives, the chelating agents able to coordinate radioactive metals are bound on the peptide N-terminus. In fact, modifications on peptide $\mathrm{N}$-terminus do not affect receptor binding that is essentially due to the interaction of receptor N-terminal extradomain with C-terminal fragment of the peptide ligand, as demonstrated by NMR studies ${ }^{85}$ and theoretical calculations. ${ }^{86}$

On the basis of these data, Accardo et al, in the last 10 years, developed a wide class of CCK 8 decorated supramolecular aggregates (Naposomes) in order to delivery contrast agents and drugs, thus acting like theranostics (Table 3) ${ }^{87}$ Naposomes are formulated by amphiphilic molecules containing a hydrophobic moiety with two C18 aliphatic chains able to stabilize the aggregates in water 
Table 3 Others receptor binding peptide coupled supramolecular aggregates

\begin{tabular}{|c|c|c|c|c|c|}
\hline Receptor & Peptide sequence & Peptide conjugation & Aggregates and lipid composition & Drug & References \\
\hline $\mathrm{CCK}_{1}-\mathrm{CCK}_{2}$ & $\begin{array}{l}\text { CCK8 } \\
\text { DYMGWMDF-NH }\end{array}$ & $\begin{array}{l}\text { CCK8 amphiphilic solid phase } \\
\text { synthesis }\end{array}$ & Micelle: $(\mathrm{Cl} 8)_{2}(\mathrm{AdOO})_{5} \mathrm{CCK} 8$ & DOX & 90 \\
\hline $\mathrm{CCK}_{1}-\mathrm{CCK}_{2}$ & $\begin{array}{l}\text { CCK8 } \\
\text { DYMGWMDF-NH }\end{array}$ & $\begin{array}{l}\text { CCK8 amphiphilic solid phase } \\
\text { synthesis }\end{array}$ & $\begin{array}{l}\text { Liposome: }(\mathrm{Cl})_{2} \text { DOTA, }(\mathrm{Cl} 8)_{2} \\
(\text { AdOO })_{5} \mathrm{CCK} 89: 1 \text { molar ratio }\end{array}$ & DOX & 91 \\
\hline $\mathrm{CCK}_{1}-\mathrm{CCK}_{2}$ & $\begin{array}{l}\text { CCK8 } \\
\text { DYMGWMDF-NH }\end{array}$ & $\begin{array}{l}\text { CCK8 amphiphilic solid phase } \\
\text { synthesis }\end{array}$ & $\begin{array}{l}\text { Bilayer-liposome: }(\mathrm{Cl} 8)_{2} \text { DTPAGlu/ } \\
(\mathrm{Cl})_{2} \mathrm{PEG}_{2000} \mathrm{CCK} 8 \text { in ratio } 7: 3\end{array}$ & DOX ${ }^{\prime \prime \prime} \ln$ & 89 \\
\hline LHRH & $\begin{array}{l}\text { Gonadorelin } \\
\text { Pyr-HWSTGLRPGNH }\end{array}$ & $\begin{array}{l}\text { Gonadorelin-SH- Mal-Peg- } \\
\text { DSPE }\end{array}$ & $\begin{array}{l}\text { Liposome: HSPC/Chol/mPEG-DSPE/ } \\
\text { Gon-PEG-DSPE 90:10:0.4 0.1\% }\end{array}$ & MTX & 107 \\
\hline LHRH & $\begin{array}{l}\text { Gonadorelin } \\
\text { Pyr-HWSTGLRPGNH }\end{array}$ & $\begin{array}{l}\text { Gonadorelin-SH- Mal-Peg- } \\
\text { DSPE }\end{array}$ & $\begin{array}{l}\text { Liposome: HSPC/Chol/mPEG-DSPE/ } \\
\text { Gon-PEG-DSPE 90:10:0.4 0.1\% }\end{array}$ & MTX & 108 \\
\hline Neurotensin & RRPYIL Nt[8-13] & Solid phase synthesis & Liposome: DOPC-NT4Lys $\left(\mathrm{Cl}\right.$ 8) ${ }_{2}$ 97:3 & DOX & 111 \\
\hline Neurotensin & $\begin{array}{l}\text { RRPYIL Nt[8-13], } \\
\text { QLYENKPRRPYIL Nt[1-13] }\end{array}$ & Solid phase synthesis & $\begin{array}{l}\text { Liposome: DOPC (NT8-I3)L-(CI8) } \\
\text { and DOPC (NTI-I3)L-(Cl8 })_{2}\end{array}$ & DOX & 112 \\
\hline
\end{tabular}

Abbreviations: AdOO, 8-amino-3,6-dioxaoctanoic acid; CCK, cholecystokinin; DOPC, I,2-Dioleoyl-sn-glycero-3-phosphocholine; DOX, doxorubicin; DSPE, I,2-distearoylsn-glycero-3-phosphoethanolamine; LHRH, luteinizing hormone releasing hormone; MTX, methotrexate; PEG, polyethylene glycol.

solution. The hydrophilic shell contains a chelating agent such as DOTA or DTPA or their metal complexes, and the CCK8 bioactive peptide. The chelating agent plays a double task: i) it gives the aggregation driving force for the presence of negative charges; and ii) it acts as polydentate ligand by complexing with high stability paramagnetic ( $\mathrm{Gd}[\mathrm{III}])$ or radioactive ( ${ }^{111} \mathrm{In}[\mathrm{III}],{ }^{67} \mathrm{Ga}[\mathrm{III}],{ }^{68} \mathrm{Ga}[\mathrm{III}],{ }^{99 \mathrm{~m}} \mathrm{Tc}[\mathrm{V}],{ }^{177} \mathrm{Lu}[\mathrm{III}]$, or $\left.{ }^{64} \mathrm{Cu}[\mathrm{II}]\right)$ metal ions for imaging application by MRI, PET, and scintigraphy. Naposomes can be obtained by selfassembling amphiphilic monomers containing in the same molecule: i) the hydrophobic moiety with two $\mathrm{C} 18$ aliphatic chains; ii) the chelating agent or its metal complexes; iii) the bioactive CCK8 peptide; and iv) PEG spacers of appropriate length to allow the exposure of the bioactive moiety on the external surface of the resulting aggregate. ${ }^{88}$ The shape and the size of the resulting Naposomes can be modulated by adding commercial phospholipids, such as DOPC, to the synthetic amphiphilic monomer.

Another class of Naposomes can be formulated by combining together two amphiphilic monomers (Figure 4). The first monomer contains the CCK8 peptide, a PEG spacer and two $\mathrm{C} 18$ hydrocarbon chains, while the second monomer contains the DOTA or DTPA chelating agent and the same hydrophobic moiety (general formula $(\mathrm{C} 18)_{2}$ LCCK 8 and (C18) $)_{2} \mathrm{CA}$, respectively). The morphology and size of the resulting aggregates (micelles, liposomes, or open bilayers) are influenced by several parameters, such as $\mathrm{pH}$, ionic strength, monomer structure (length of polioxiethylene spacers), and composition and formulation procedure (dissolution in buffered solution or well-assessed procedures based on sonication and extrusion). ${ }^{87}$

All aggregates are able to act as theranostics, carrying contrast agents like Gd ions for MRI imaging, radioactive metals for nuclear medicine techniques, and chemotherapy drugs.

Theranostic effects were demonstrated as proof of concept for the aggregate based on (C18) $)_{2}$ DTPAGlu and (C18) PEG $_{2000}$ CCK8 monomers in 70:30 ratio. ${ }^{89}$ The uptake of ${ }^{111}$ In-radiolabeled aggregates by A431 cells overexpressing CCK2-R via transfection was demonstrated by in vitro experiments at $4^{\circ} \mathrm{C}$ and at $37^{\circ} \mathrm{C}$. In vivo biodistribution showed that the overall retention of radiolabeled aggregates in mice at 18 hours is very high, with essentially no excretion of radioactivity over the observation period. Moreover, the radioactivity retention of the receptorpositive xenografts was always higher than in their respective controls (Figure 4). Finally, cytotoxicity assays were performed by incubating the cells with peptide-containing aggregates filled with DOX in ratio 2:1 per aggregate. The overexpressing receptor cells survive significantly less than the control cells.

DOX has been also encapsulated in micelles obtained by self-assembling of $(\mathrm{C} 18)_{2}(\mathrm{AdOO})_{5} \mathrm{CCK} 8$ monomers. ${ }^{90}$ These nanostructures, fully characterized by structural measurements, are able to encapsulate poorly water soluble molecules, such as pyrene, and DOX drug in their hydrophobic compartment. The encapsulation process, followed and quantified by fluorescence techniques, shows a strong preference of DOX for the inner hydrophobic environment of these nanostructures.

Further aggregates were formulated by adding the same $(\mathrm{C} 18)_{2}(\mathrm{AdOO})_{5} \mathrm{CCK} 8$ monomer to $(\mathrm{C} 18)_{2}$ DOTA in a 10:90 molar ratio. ${ }^{91}$ (C18) ${ }_{2}$ DOTA monomer that is responsible for aggregate shape and size allows the obtainment of stable liposomes in water solution. DOX loading content is above $95 \%$ of the total drug added with a drug/lipid weight 


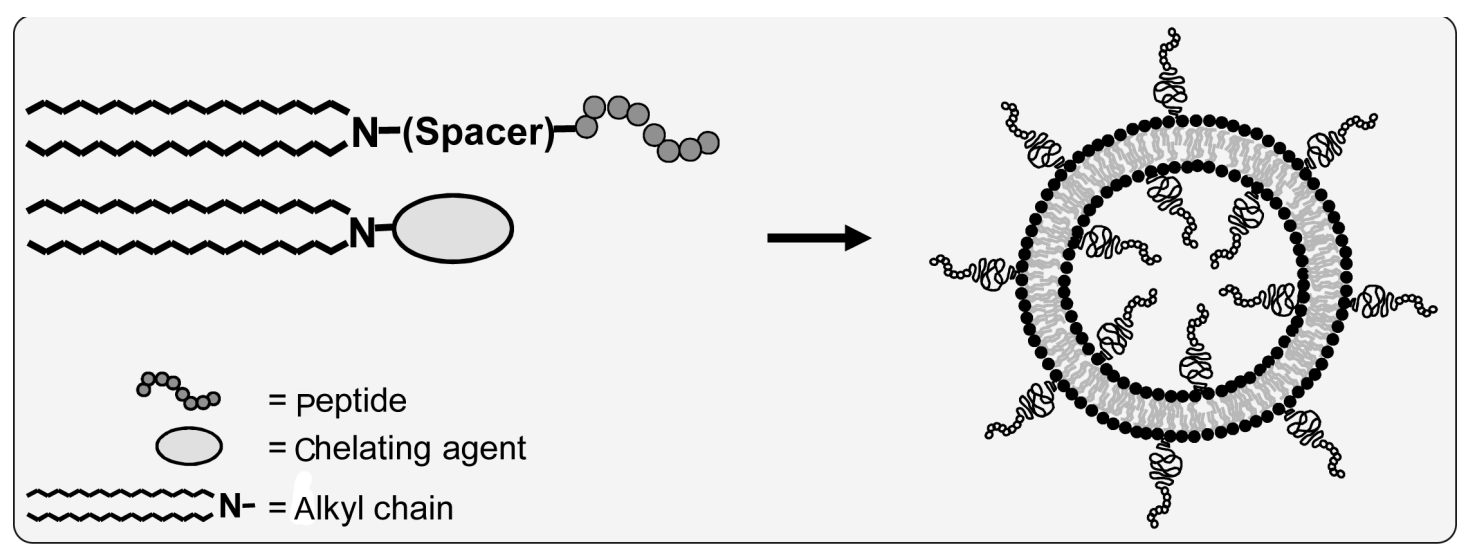

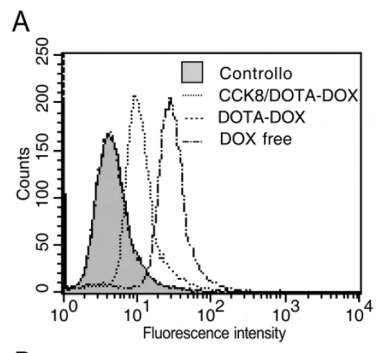

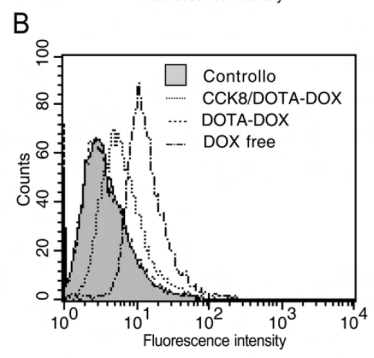

C

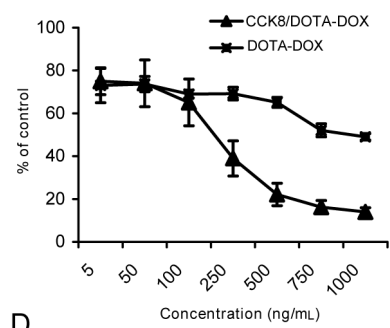

D

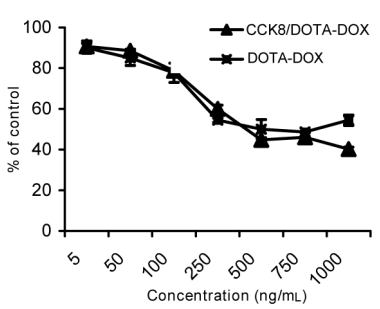

E

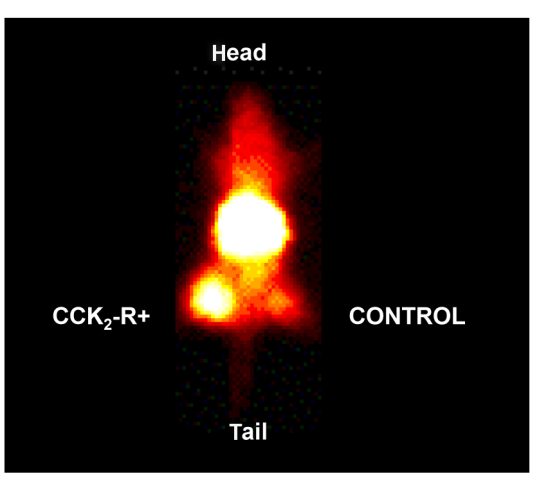

Figure 4 Scheme of Naposomes formulation and their in vitro and in vivo behavior. Flow cytometric analysis of association of liposomal DOX and free DOX with human cells. Notes: A43I cells $(\mathbf{A})$ and HUVEC cells $(\mathbf{B})$ at a density of $1.3 \cdot 10^{6}$ cells $/ \mathrm{mL}$ were incubated with CCK8/DOTA-DOX, DOTA-DOX, and free DOX at a final concentration of I $\mu \mathrm{g} D O X / \mathrm{mL}$ for I hour at $48^{\circ} \mathrm{C}$. Untreated cells served as negative control while free doxorubicin solution was used as positive control. The untreated cells (negative controls) and cells incubated with non-specific DOTA-DOX give identical behavior with overlapping curves. (C and D) Cytotoxicity of liposomal DOX against human cells on $43 \mathrm{I}$ cells and HUVEC, respectively. Cells were incubated with CCK8/DOTA-DOX and DOTA-DOX at different concentration ranging between 0 and $1,000 \mathrm{ng} / \mathrm{mL}$ at $37^{\circ} \mathrm{C}$. After 8 hours, the medium was removed and after an additional 72 hours, an MTT assay was performed. Data are expressed as percent of negative control. (E) $\gamma$-camera image (dorsal view) obtained prior to dissection of one of the animals $18 \mathrm{~h}$ after injection of radiolabeled aggregates clearly shows higher concentration of the radiolabel in the receptor positive xenograft (+, left flank) compared with the control tumor (-, right flank). (A-D) Reproduced with permission from John Wiley and Sons. Morisco A, Accardo A, Tesauro D, Palumbo R, Benedetti E, Morelli G. Peptide-labeled supramolecular aggregates as selective doxorubicin carriers for delivery to tumor cells. Biopolymers. 2011;96:88-96.' Copyright (C 201I Wiley Periodicals, Inc. (E) Reproduced with permission from John Wiley and Sons. Accardo A, Tesauro D, Aloj L, et al. Peptide-containing aggregates as selective nanocarriers for therapeutics. ChemMedChem. 2008;3(4):594-602.89 Copyright @ 2008 WILEY-VCH Verlag GmbH \& Co. KGaA, Weinheim.

Abbreviations: CCK, cholecystokinin; DOTA, I,4,7,I0-tetraazacyclododecane-N,N',N",N"'-tetraacetic acid; DOX, doxorubicin; HUVEC, human umbilical vein endothelial cell; MTT, 3-(4,5-dimethyl-2-thiazolyl)-2,5-diphenyl-2H-tetrazolium bromide.

(w)/w ratio of 0.134 . The cellular uptake of the peptide containing targeted liposomal DOX on A431 and HUVEC cells was 70- and 8-fold higher than that for non-targeted liposomes, respectively, indicating that the bioactive CCK8 peptide is able to enhance uptake into the A431 carcinoma cells and, at lower amounts, in the endothelial HUVEC cells (Figure 4).

\section{Bombesin based delivery systems}

Four receptor-subtypes associated with the Bombesin like peptides (BLP) family have been identified: sub- type 1 (termed GRP-R or BB2); subtype 2 (termed NMB-R or BB1); subtype 3 (termed BRS-3) classified as an orphan receptor because its natural ligand is yet to be identified; and subtype 4 (termed BB4). In addition to their physiological functions, these receptors have been found overexpressed in prostate, breast, small cell lung, ${ }^{92}$ ovarian, and gastrointestinal stromal tumors. ${ }^{93}$

Peptides able to bind these receptors belong to a family of brain-gut peptides. BN (bombesin) is a 14-amino-acid peptide present in amphibian tissues, whereas GRP, its human counterpart, consists of 27 amino acids. GRP and BN differ 
by only one of the ten $\mathrm{C}$-terminal residues playing similar biological activities. ${ }^{94}$ GRP acts primarily in the central and enteric nervous systems where it regulates several physiological processes including satiety, thermoregulation, circadian rhythm, smooth muscle contraction, immune function, as well as the release of other peptide hormones.

The fourteen $\mathrm{BN}$ residues, its eight-residues $\mathrm{C}$-terminal peptide sequence ([7-14]BN), and many other BN analogs acting as agonist or antagonists, have been modified to selectively carry diagnostic or therapeutic agents to their receptors. Many studies demonstrate that the [7-14]BN fragment conjugated on the $\mathrm{N}$-terminus with amino acid linkers, aliphatic or hydrophilic moiety preserves the affinity for receptors. ${ }^{95,96}$ Moreover, the pan-bombesin analog [ $\beta$-Ala11, Phe13, Nle14] BN[7-14] conjugated through a linker to dextran covalently cross-linked to iron oxide (CLIO) is able to bind to PC-3 cells overexpressing GPR receptors, as indicated by MRI studies. ${ }^{97}$

\section{Liposomes and micelles}

On the basis of MRI results, Accardo et al developed new bombesin based supramolecular aggregates acting as theranostic agents (Table 4). ${ }^{98}$ They were obtained by the combination of two amphiphilic synthetic monomers: a first, more abundant, monomer based on a lysine residue carrying a DOTA chelating agent on the epsilon amino function and an hydrophobic moiety with two $\mathrm{C} 18$ chains on the alpha amino function; and a second monomer containing the same hydrophobic moiety, PEG spacers, and the 7-14 BN peptide fragment. The DOTA containing monomer drives to form stable liposomes in water solution independently from the presence of $10 \%$ in peptide monomer, as demonstrated by SANS (small angle neutron scattering) and DLS (dynamic light scattering) techniques. The liposome hydrodynamic radius and bilayer thickness were found to be around $200 \mathrm{~nm}$ and $4 \mathrm{~nm}$, respectively. This structure is different from that observed for similar aggregates, in which the presence of DTPAGlu chelating agent in the most abundant amphiphilic monomer produces highly polydisperse aggregates (rod-like micelles, open bilayers, and vesicles). This behavior could be explained on the basis of the lower negative charge $(-3)$ of DOTA versus DTPAGlu (-5); a decrease of the electrostatic repulsion between the headgroups favors the formation of large and low curvature aggregates, such as liposomes. Different systems were studied depending on the length of the PEG spacer in the peptide containing monomer. In vitro data of radioactive labeled ${ }^{111} \mathrm{In}-(\mathrm{C} 18)_{2} \mathrm{DOTA} /$ (C18) ${ }_{2} \mathrm{AdOO}_{5}-[7-14] \mathrm{BN}$ liposomes show specific binding to receptor expressing cells, while the presence of a longer PEG (Peg3000) on the external liposomal surface hides the bioactive peptide, preventing receptor binding. In vivo experiments display the expected biological behavior of aggregates of such size and molecular composition, and preliminarily confirm the aggregates' ability to specifically target receptor expressing xenografts. At later stages, liposomes based on coaggregation of 1,2-distearoyl-sn-glycero-3-phosphocholine (DSPC) phospholipid with the amphiphilic synthetic monomer MonY-BN were developed. ${ }^{99}$ This monomer contains, in a single molecule, the [7-14]BN peptide fragment, the DTPA chelating agent, the hydrophobic moiety with two C18 alkyl chains, and a PEG spacer of 1500 Daltons. DOX loading capability of DSPC/MonY-BN (97:3 molar ratio) liposomes is 0.20 (drug/lipid, w/w), higher than that found for the approved liposomal drug DOXIL (0.125). The selective liposome binding was evaluated in vitro by gamma counting experiments after radiolabeling of liposomes with ${ }^{111} \mathrm{In}$ isotopes. Cytotoxic assays showed significantly lower cell survival after cell incubation with DSPC/MonY-BN/DOX liposomes, compared to DSPC/DOX treated cells. Intravenous treatment of PC-3 xenograft-bearing mice produced

Table 4 Bombesin analogs labeled supramolecular aggregates or nanoparticles

\begin{tabular}{|c|c|c|c|c|}
\hline Peptide sequence & Peptide conjugation & Aggregates and lipid composition & Drug & References \\
\hline $\begin{array}{l}{[7-I 4] \text { BN }} \\
\text { QWAVGHML-NH }\end{array}$ & $\begin{array}{l}\text { BN amphiphilic solid phase } \\
\text { synthesis }\end{array}$ & $\begin{array}{l}\text { Liposome: }(\mathrm{Cl} 8)_{2} \mathrm{DOTA} / \\
(\mathrm{Cl} 8)_{2}(\mathrm{AdOO})_{5} \mathrm{BN} \text { and }(\mathrm{Cl} 8)_{2} \mathrm{DOTA} / \\
(\mathrm{Cl})_{2} \mathrm{Peg}_{3000} \mathrm{BN}(9: 1 \text { molar ratio })\end{array}$ & DOX & 98 \\
\hline $\begin{array}{l}\text { [7-I4] BN } \\
\text { QWAVGHML-NH }\end{array}$ & $\begin{array}{l}\text { BN amphiphilic solid phase } \\
\text { synthesis }\end{array}$ & $\begin{array}{l}\text { Liposome: DSPC/MonY-BN } \\
\text { ( } 1: 0.03 \text { molar ratio) }\end{array}$ & DOX & 99 \\
\hline $\begin{array}{l}\text { AhoH-DPheQWAVNMeGHSta- } \\
\text { L-NH }\end{array}$ & $\begin{array}{l}\text { BN analog amphiphilic solid } \\
\text { phase synthesis }\end{array}$ & $\begin{array}{l}\text { Liposome: DSPC/MonY-BN-AAI } \\
\text { (I:0.03 molar ratio) }\end{array}$ & DOX & 101 \\
\hline Ac-Cys-Ahx-QWAVGHLMNH ${ }_{2}$ & $\begin{array}{l}\text { Ac-Cys-Ahx-BN } \\
\mathrm{NH}_{2} \text {-AuNP }\end{array}$ & & AuNPs & 104 \\
\hline $\begin{array}{l}\text { 7-I4 BN } \\
\text { QWAVGHML-NH }\end{array}$ & $\begin{array}{l}\text { 7-14 BN functionalized on } \\
\text { N-terminus with lipoic acid AuNPs }\end{array}$ & & AuNPs & 103 \\
\hline
\end{tabular}

Abbreviations: AdOO, 8-amino-3,6-dioxaoctanoic acid; AhOH, 21 -amino-4,7,10,13,16,19-hexaoxaheneicosanoic acid; AuNP, gold nanoparticles; Ahx, aminohexanoic acid; BN, bombesin; DOX, doxorubicin; DSPC, I,2-Distearoyl-sn-glycero-3-phosphocholine. 
higher tumor growth inhibition (60\%) compared with nonspecific liposomes $(36 \%)$ relative to control animals.

The relatively short in vivo circulation time of this natural peptide fragment suggested to many researchers that modifying peptide sequences can enhance protease stability. ${ }^{100}$ A very recent attempt was carried out, replacing the $\mathrm{Leu}^{13}-\mathrm{Met}^{14}$ C-terminal sequence with $\mathrm{Sta}^{13}-\mathrm{Leu}^{14}$, for stabilization against aminopeptidase, and inserting N-methyl-glycine in place of natural glycine in order to reinforce the Val-Gly bond that could be sensitive to carnitine enzyme. ${ }^{100}$ Moreover, Mansi et a $1^{100}$ demonstrated that replacement of Leu ${ }^{13}$ with the Sta ${ }^{13}$ residue provides antagonist properties to the peptide. Finally, the presence of D-Phe residue on the N-terminal end of the $\mathrm{BN}$ bioactive sequence increases binding and stability. DSPC/ MonY-BN-AA1/DOX liposomes containing the modified BN-AA1 bombesin sequence were able to target PC-3 cells in a selective way and provide therapeutic efficacy in PC-3 cells and PC-3 xenograft bearing mice to a slightly greater extent than DSPC/MonY-BN/DOX liposomes. ${ }^{101}$

\section{Metal nanoparticles}

Several metal nanoparticles were labeled to target BN receptors for tumor therapy and treatment monitoring. ${ }^{102}$ AuNPs have been used in photothermal therapy for the destruction or molecular surgery of cancer cells or tumors. When irradiated with a focused laser in the near-infrared region (NIR) of suitable wavelength, targeted aggregates of AuNPs can kill cancer cells. At the same time, they are carriers of anticancer drugs or contrast agents, providing synergistic advantages in oncology as it relates to molecular imaging and therapy.

Chanda et $\mathrm{al}^{103}$ synthesized a library of GRP receptor nanoplatforms by conjugating AuNPs with BN peptides. The 7-14 BN peptide was functionalized on N-terminus with lipoic acid, which contains a disulfide group able to bind AuNPs. Reactive sites on AuNPs surface allow the incorporation of varying amounts of BN peptides and provide a library of AuNP-BN conjugates with different ratios. The hydrodynamic diameter of AuNP-BNs (115-155 nm) is compatible for effective penetration within tumor vasculature, which has porosity in the 150-300 $\mathrm{nm}$ range. In vitro cellular interactions and binding affinities $\left(\mathrm{IC}_{50}\right)$ toward GRP receptors on human prostate cancer cells and in vivo studies using AuNP-BN and its radiolabeled surrogate ${ }^{198}$ exhibited high binding affinity $\left(\mathrm{IC}_{50}\right.$ in microgram ranges), providing unambiguous evidences that AuNP-BN constructs are GRP-receptor-specific. Indeed, the nanoparticles were accumulated with high selectivity in GRPreceptor-rich pancreatic acne in normal mice and in tumor cells of prostate-tumor-bearing, severe combined immunodeficient mice. More recently, Hosta-Rigau et a ${ }^{104}$ exploited the ability of BN labeled AuNPs to vehicle an analog of the RAF peptide. This pharmaceutical active peptide ligand is able to inhibit Rb-Raf-1 binding in vivo and therefore inhibits tumor growth and angiogenesis. ${ }^{105} \mathrm{BN}$ and RAF peptides were conjugated to nanoparticles by modifying gold surface with Cys residues and an aminohexanoic acid (Ahx) acting as spacer. Internalization mechanism of peptide-AuNP conjugates and enhancement of activity and selectivity of peptide multifunctionalized conjugates was observed by confocal laser scanning microscopy. Preliminary results confirm that conjugates in which $\mathrm{BN}$ is present penetrate GRPr overexpressing cells, as indicated by coloration of nanoconjugates of Ac-Cys-Ahx-BN and Ac-CysAhx-RAF inside cells due to the accumulation and reflection of the AuNP. The enhancement in activity and selectivity could contribute to a potential improvement of the efficacy of RAF for therapy by reducing the therapeutic index. Furthermore, this strategy provides an opportunity for the controlled delivery of AuNPs used as cargoes for a localized (nanometrically) therapy like the so-called molecular surgery.

\section{Other systems Lutein releasing hormone based delivery systems}

Luteinizing hormone (LH)-releasing hormone (also referred to as GNRH or LHRH) is the central regulator of reproduction via its action upon the hypothalamic-pituitary axis. The LHRH receptors are characteristically overexpressed in many different tumors, such as breast, ovarian, endometrial, and prostate cancers, but barely expressed in healthy visceral organs. The elevated expression of LHRH receptors in various cancers makes it possible to use them as target moieties to deliver cytotoxic agents to these tumors. ${ }^{106}$ Some small peptide LHRH analogs were able to recognize a broad variety of tumors, but not normal cells. Targeting these small peptides has certain advantages, including ease of preparation, lower antigenicity, and increased stability over the use of conventional protein macromolecules.

Liposomes were prepared using a lipid molar ratio HSPC/ Chol/mPEG-DSPE 90:10:0.4, and 0.1\% mol Mal-PEG-DSPE was further inserted for ligand conjugation. Gonadorelin (Pyr-His-Trp-Ser-Tyr-Gly-Leu-Arg-Pro-Gly- $\mathrm{NH}_{2}$ ) was first thiolated through incubation with Traut's reagent. Thiolated gonadorelin was chemically coupled to $\mathrm{N}$-[(3-maleimide1-oxopropyl) aminopropyl polyethylene glycol-carbamyl] distearoylphosphatidylethanolamine via a thioether bond and subsequently inserted into polyethylene glycol-grafted liposomes. Efficient transfer of gonadorelin-PEG-DSPE from 
micelles into the outer monolayer of liposomes was achieved at a temperature above the phase transition of the lipids (around $60^{\circ} \mathrm{C}$ ) to obtain the gonadorelin modified liposomes. MTX was encapsulated into the gonadorelin-modified or control nontarget liposome formulation using transmembrane ammonium sulfate gradient-driven loading procedures. The size of the liposomes was in the range of 120-150 $\mathrm{nm}$. The size of the gonadorelin modified liposomes was found to be 15-20 nm larger than the original liposomes. The zeta potential was slightly lower after the ligand conjugation, due to the presence of peptides attached to the liposomal membrane via a longer PEG linker. Regardless of this, the encapsulation of MTX did not significantly affect the particle size of the liposome. ${ }^{107}$

The intracellular uptake experiments were carried out on MCF-7 cells with either gonadorelin modified MTX loaded liposomes (LHRH-MTX-SL) or non-target MTX loaded liposomes (MTX-SL) at a dose of $0.2 \mathrm{mg}$ of total lipids $(10 \mu \mathrm{g} / \mathrm{mL}$ as MTX) per dish. After 4 hours incubation at $37^{\circ} \mathrm{C}$, the internalized liposomes were visualized using a confocal laser scanning microscope, resulting in an intense fluorescence in both the cytoplasm and at the cellular membrane. Meanwhile, for MTX-SL, the fluorescence intensity was much lower overall and mainly located at the cell surface respectively ${ }^{108}$ (Figure 5).

\section{Neurotensin based delivery systems}

Neurotensin (NT) is a 13 amino acid peptide isolated from calf hypothalamus; its amino acid sequence is QLYENKPRRPYIL, with the C-terminus displaying the 8-13 (RRPYIL) active fragment. NT has the dual function of neurotransmitter or neuromodulator in the nervous system and local hormone in the periphery. NT receptor type 1 (NTR1) is overexpressed in severe malignancies, such as small cell lung cancer and colon, pancreatic, and prostate carcinomas. ${ }^{17}$ NT has additional well-established targets on the cell surface: NT receptor 2; NT receptor 3 (NTR3, or sortilin); and SorLA (LR11) - these latter two membrane proteins belong to the novel Vps10p-domain family. ${ }^{109}$

NT shows a very short half-life in vivo; Falciani et al designed tetrabranched peptides (NT4) containing four copies of the active NT sequence and acting as tumor targeting agents. ${ }^{110}$ It is well known that peptides synthesized in a branched arrangement not only become resistant to proteases but also increase linear peptide biological activity through multivalent binding. Additionally, branched NT peptides have been proven to discriminate between binding of tumor versus healthy tissue in human surgical samples, validating increasing interest.

Target liposomes were prepared by mixing together DOPC phospholipids and (C18) $)_{2}$ ys (NT8-13) $)_{4}$ monomer
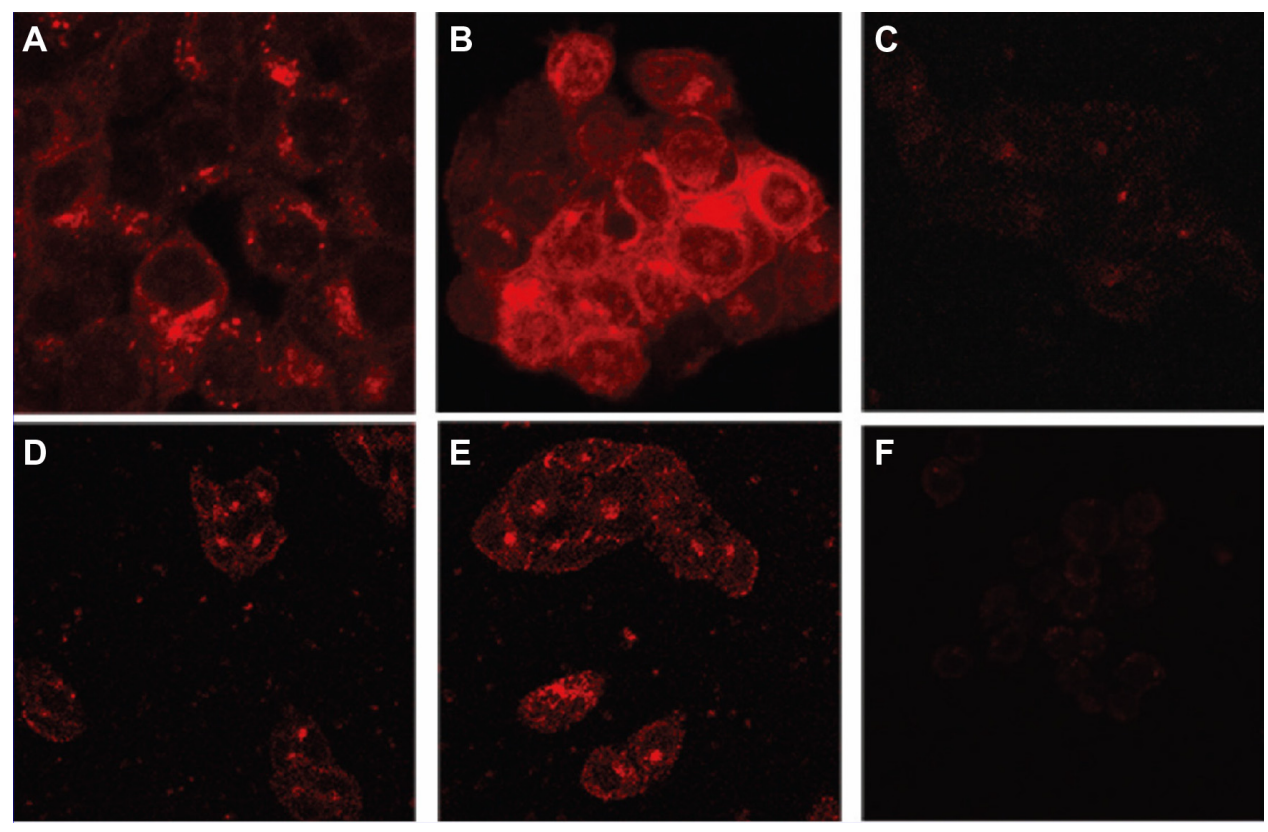

Figure 5 Liposomes encapsulating mitoxantrone uptake in various cell lines followed by confocal laser scanning fluorescence microscopy. Cell lines were treated with either LHRH-MTX-SL or MTX-SL for 4 hours at $37^{\circ} \mathrm{C}$. (A) LHRH-MTX-SL in LHRH receptor high-expressing MCF-7 cells; (B) MTX-SL in LHRH receptor high-expressing MCF-7 cells; (C) MCF-7 cells treated with drug-free medium used as a control; (D) LHRH-MTX-SL in LHRH receptor low-expressing SK-OV-3 cells; (E) MTX-SL in LHRH receptor low-expressing SK-OV-3 cells; (F) SKOV-3 cells treated with drug-free medium used as a control.

Note: Copyright (C) 2010. Reproduced with permission of Dove Medical Press. He Y, Zhang L, Song C. Luteinizing hormone-releasing hormone receptor-mediated delivery of mitoxantrone using LHRH analogs modified with PEGylated liposomes. Int J Nanomedicine. 2010;5:697-705. ${ }^{108}$

Abbreviations: LHRH, luteinizing hormone releasing hormone; MTX, methotrexate; SL, loaded liposomes. 

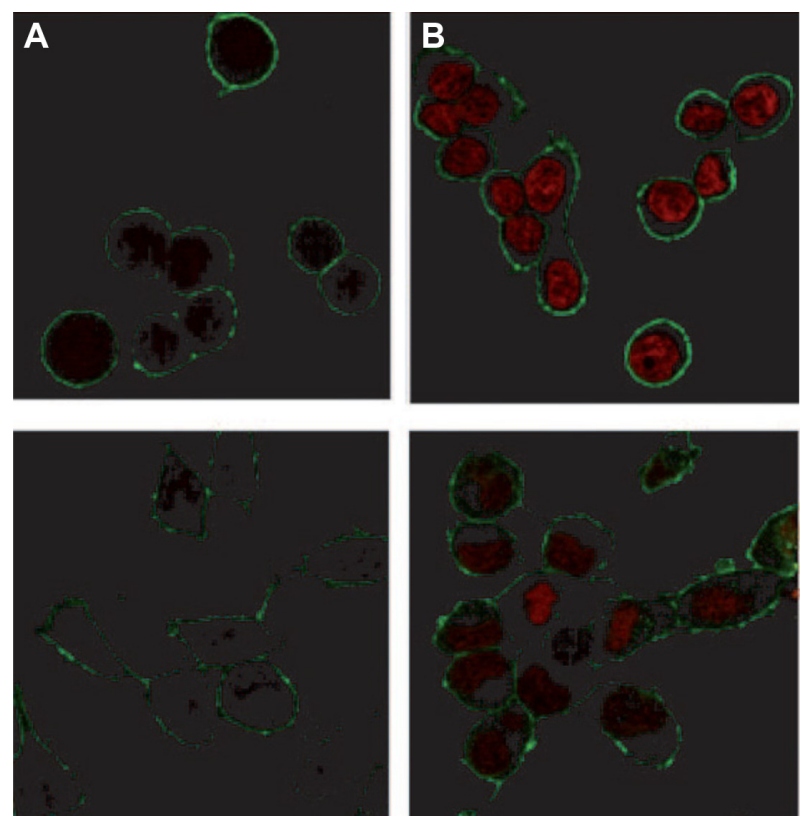

Figure 6 Confocal microscopy of (A) HT29 and (B) TE67I cells incubated with DOPC-(CI8) $)_{2}$ Lys(NT8-13) $)_{4}$ DOX liposomes (200 nm, right) and with DOPC-DOX liposomes $\left(200 \mathrm{~nm}\right.$, left) for 2 hours at $37^{\circ} \mathrm{C}$. Plasma membranes were stained with lectin-FITC (green).

Note: Reproduced with permission from Falciani C, Accardo A, Brunetti J, et al. Target-selective drug delivery through liposomes labeled with oligobranched neurotensin peptides. ChemMedChem. 201 I;6(4):678-685."'I Copyright (C) 20II WILEY-VCH Verlag GmbH \& Co. KGaA, Weinheim.

Abbreviations: DOPC, I,2-dioleoyl-sn-glycero-3-phosphocholine; DOX, doxorubicin; FITC, fluorescein isothiocyanate.

obtained by using a solid phase synthesis. ${ }^{111}$ In vitro cytotoxic results of functionalized liposomes loaded with DOX show a clear advantage, in comparison to native liposomes, in tumor cell drug internalization, both in HT29 and TE671 cells. Fluorescent-activated cell sorting (FACS) analyses are in line with these results, showing a fluorescence signal increase in both cell lines when NT4 decorated liposomes are compared to the non-functionalized analogs (Figure 6). All of these effects can be attributed to a higher rate of internalization of the decorated liposomes.

Recently, the comparison of the branched (NT4) versus linear (NT) peptides demonstrated liposomes decorated with branched peptides present a better profile in drug delivery, with respect to liposomes decorated with the correspondent monomeric peptides. ${ }^{112}$

\section{Conclusion and future perspectives}

Beside new therapies and new drugs, the innovative administration methods of well tested active principles can represent an additional weapon in the fight against cancer. Compared to conventional small molecule-based therapy, nano-therapeutic systems have several potential advantages: they can remain in the circulation for an extended period of time when injected intravenously, and present high payload capacity, reduced toxicity to healthy tissues, and improved antitumor efficacy. The active targeting by means of drug encapsulated nanoparticles decorated with targeting bioactive moieties represents the next frontier in drug delivery: it reduces drug side effects and increases the therapeutic index. Peptides, based on their chemical and biological properties, could have a prevalent role in directing drug encapsulated nanoparticles, such as liposomes, micelles, or hard nanoparticles, toward tumor tissues. Therapeutic agents based on nanovectors decorated with peptides targeting GPCRs membrane receptors overexpressed by cancer cells have been reviewed in this article. Despite the promising in vitro and in vivo results here described, all compounds reported in literature are still in preclinical phases. For most of the described systems, it is possible to schedule Phase I clinical trials, which can definitively legitimize the use of peptide decorated nanoparticles as target selective delivery systems for cancer therapy. Moreover, many efforts should be made to search for other peptide sequences to decorate drug encapsulated nanovectors.

\section{Acknowledgments}

The authors would like to thank Italian Minister for Research (MIUR) for financial support under PRIN 2009WCNS5C and FIRB RBRN07BMCT founding projects.

\section{Disclosure}

The authors report no conflicts of interest in this work.

\section{References}

1. Richardson PF. Nanotechnology therapeutics in oncology-recent Developments and future outlook. Annu Rep Med Chem. 2012;47: 239-252.

2. Levchenko TS, Hartner WC, Torchilin VP. Liposomes for cardiovascular targeting. Ther Deliv. 2012;3(4):501-514.

3. Maradana MR, Thomas R, O'Sullivan BJ. Targeted delivery of curcumin for treating type 2 diabetes. Mol Nutr Food Res. 2013;57(9): $1550-1556$.

4. Levesque JP, Winkler IG. It takes nerves to recover from chemotherapy. Nat Med. 2013;19(6):669-671.

5. Matsumura Y, Maeda H. A new concept for macromolecular therapeutics in cancer chemotherapy: mechanism of tumoritropic accumulation of proteins and the antitumor agent smancs. Cancer Res. 1986;46(12 Pt 1):6387-6392.

6. Salmaso S, Caliceti P. Stealth properties to improve therapeutic efficacy of drug nanocarriers. J Drug Deliv. 2013;2013:1-19.

7. Gabizon AA. Liposome circulation time and tumor targeting: implications for cancer chemotherapy. Adv Drug Deliv Rev. 1995;16:285-294.

8. Aliabadi HM, Shahin M, Brocks DR, Lavasanifar A. Disposition of drugs in block copolymer micelle delivery systems: from discovery to recovery. Clin Pharmacokinet. 2008;47(10):619-634.

9. Kwon GS, Kataoka K. Block copolymer micelles as long-circulating drug vehicles. Adv Drug Delivery Rev. 1995;16:295-309. 
10. Shin HC, Alani AW, Rao DA, Rockich NC, Kwon GS. Multi-drug loaded polymeric micelles for simultaneous delivery of poorly soluble anticancer drugs. J Control Release. 2009;140(3):294-300.

11. Kim SC, Kim DW, Shim YH, et al. In vivo evaluation of polymeric micellar paclitaxel formulation: toxicity and efficacy. $J$ Control Release. 2001;72(1-3):191-202.

12. Torchilin VP. Structure and design of polymeric surfactant-based drug delivery systems. J Control Release. 2001;73(2-3):137-172.

13. Torchilin VP. Micellar nanocarriers: pharmaceutical perspectives. Pharm Res. 2007;24(1):1-16.

14. Kataoka K, Kwon GS, Yokoyama M, Okano T, Sakurai Y. Block copolymer micelles as vehicles for drug delivery. $J$ Control Release. 1993;24:119-132.

15. Kataoka K, Matsumoto T, Yokoyama M, et al. Doxorubicin-loaded poly(ethylene glycol)-poly(beta-benzyl-L-aspartate) copolymer micelles: their pharmaceutical characteristics and biological significance. J Control Release. 2000;64:143-153.

16. Torchilin VP, Trubetskoy VS, Whiteman KR, Caliceti P, Ferruti P, Veronese FM. New synthetic amphiphilic polymers for steric protection of liposomes in vivo. J Pharm Sci. 1995;84(9):1049-1053.

17. Johnson SD, Anderson JM, Marchant RE. Biocompatibility studies on plasma polymerized interface materials encompassing both hydrophobic and hydrophilic surfaces. J Biomed Mater Res. 1992;26(7):915-935.

18. Benahmed A, Ranger M, Leroux JC. Novel polymeric micelles based on the amphiphilic diblock copolymer poly(N-vinyl-2-pyrrolidone)block-poly(D,L-lactide). Pharm Res. 2001;18(3):323-328.

19. Luppi B, Cerchiara T, Bigucci F, Di Pietra AM, Orienti I, Zecchi V. Crosslinked poly(methyl vinyl ether-co-maleic anhydride) as topical vehicles for hydrophilic and lipophilic drugs. Drug Deliv. 2003;10(4):239-244.

20. Luppi B, Bigucci F, Cerchiara T, et al. Micelles based on polyvinyl alcohol substituted with oleic acid for targeting of lipophilic drugs. Drug Deliv. 2005;12(1):21-26.

21. Bangham AD, Horne RW. Negative staining of phospholipids and their structural modification by surface-active agents as observed in the electron microscope. J Mol Biol. 1964;8:660-668.

22. Klibanov AL, Maruyama K, Torchilin VP, Huang L. Amphipathic polyethyleneglycols effectively prolong the circulation time of liposomes. FEBS Lett. 1990;268(1):235-237.

23. Krown SE, Northfelt DW, Osoba D, Stewart JS. Use of liposomal anthracyclines in Kaposi's sarcoma. Semin Oncol. 2004;31(6 Suppl 13): $36-52$.

24. Rose PG. Pegylated liposomal doxorubicin: optimizing the dosing schedule in ovarian cancer. Oncologist. 2005;10(3):205-214.

25. Lehár J, Krueger AS, Avery W, et al. Synergistic drug combinations tend to improve therapeutically relevant selectivity. Nat Biotechnol. 2009;27(7):659-666.

26. Wang $\mathrm{H}$, Zhao Y, Wu Y, et al. Enhanced anti-tumor efficacy by codelivery of doxorubicin and paclitaxel with amphiphilic methoxy PEG-PLGA copolymer nanoparticles. Biomaterials. 2011;32(32): 8281-8290.

27. Duan J, Mansour HM, Zhang Y, et al. Reversion of multidrug resistance by co-encapsulation of doxorubicin and curcumin in chitosan/poly(butyl cyanoacrylate) nanoparticles. Int J Pharm. 2012; 426(1-2):193-201.

28. Zhang L, Gu FX, Chan JM, Wang AZ, Langer RS, Farokhzad OC. Nanoparticles in medicine: therapeutic applications and developments. Clin Pharmacol Ther. 2008;83(5):761-769.

29. Jordan A, Scholz R, Maier-Hauff K, et al. The effect of thermotherapy using magnetic nanoparticles on rat malignant glioma. J Neurooncol. 2006;78(1):7-14.

30. Frimpong RA, Hilt JZ. Magnetic nanoparticles in biomedicine: synthesis, functionalization and applications. Nanomedicine (Lond). 2010;5(9):1401-1414.

31. Jabr-Milane LS, van Vlerken LE, Yadav S, Amiji MM. Multi-functional nanocarriers to overcome tumor drug resistance. Cancer Treat Rev. 2008;34(7):592-602.
32. Kievit FM, Wang FY, Fang C, et al. Doxorubicin loaded iron oxide nanoparticles overcome multidrug resistance in cancer in vitro. $J$ Control Release. 2011;152(1):76-83.

33. Roy I, Ohulchanskyy TY, Pudavar HE, et al. Ceramic-based nanoparticles entrapping water-insoluble photosensitizing anticancer drugs: a novel drug-carrier system for photodynamic therapy. JAm Chem Soc. 2003;125(26):7860-7865.

34. Xiong XB, Huang Y, Lu WL, et al. Enhanced intracellular delivery and improved antitumor efficacy of doxorubicin by sterically stabilized liposomes modified with a synthetic RGD mimetic. J Control Release. 2005;107(2):262-275.

35. Witzig TE. Yttrium-90-ibritumomab tiuxetan radioimmunotherapy: a new treatment approach for B-cell non-Hodgkin's lymphoma. Drugs Today (Barc). 2004;40(2):111-119.

36. Foss FM. DAB(389)IL-2 (ONTAK): a novel fusion toxin therapy for lymphoma. Clin Lymphoma. 2000;1(2):110-116; discussion 117.

37. Mårlind J, Kaspar M, Trachsel E, et al. Antibody-mediated delivery of interleukin-2 to the stroma of breast cancer strongly enhances the potency of chemotherapy. Clin Cancer Res. 2008;14(20): 6515-6524.

38. Wiseman GA, White CA, Witzig TE, et al. Radioimmunotherapy of relapsed non-Hodgkin's lymphoma with zevalin, a 90Y-labeled anti-CD20 monoclonal antibody. Clin Cancer Res. 1999;5(Suppl 10): 3281s-3286s.

39. Hilgenbrink AR, Low PS. Folate receptor-mediated drug targeting: from therapeutics to diagnostics. J Pharm Sci. 2005;94(10):2135-2146.

40. Choi CH, Alabi CA, Webster P, Davis ME. Mechanism of active targeting in solid tumors with transferrin-containing gold nanoparticles. Proc Natl Acad Sci U S A. 2010;107(3):1235-1240.

41. Reubi JC. Peptide receptors as molecular targets for cancer diagnosis and therapy. Endocr Rev. 2003;24(4):389-427.

42. Ginj M, Zhang H, Waser B, et al. Radiolabeled somatostatin receptor antagonists are preferable to agonists for in vivo peptide receptor targeting of tumors. Proc Natl Acad Sci U S A. 2006;103(44): 16436-16441.

43. Chan KY, Vermeersch S, de Hoon J, Villalón CM, MaassenvandenbrinkA. Potential mechanisms of prospective antimigraine drugs: a focus on vascular (side) effects. Pharmacol Ther. 2011;129(3):332-351.

44. Allen FH, Pitchford NA. Conformational analysis from crystallographic data In: Codding PW editors. Structure Based Drug Design. The Netherlands; The Netherlands Kluwer Academic Publishers: 1998:15-26.

45. Pande J, Szewczyk MM, Grover AK. Phage display: concept, innovations, applications and future. Biotechnol Adv. 2010;28(6):849-858.

46. Feldborg LN, Jølck RI, Andresen TL. Quantitative evaluation of bioorthogonal chemistries for surface functionalization of nanoparticles. Bioconjug Chem. 2012;23(12):2444-2450.

47. Xiong XB, Huang Y, Lu WL, et al. Enhanced intracellular delivery and improved antitumor efficacy of doxorubicin by sterically stabilized liposomes modified with a synthetic RGD mimetic. J Control Release. 2005;107(2):262-275.

48. Danhier F, Le Breton A, Préat V. RGD-based strategies to target alpha(v) beta(3) integrin in cancer therapy and diagnosis. Mol Pharm. 2012;9(11):2961-2973.

49. Binétruy-Tournaire R, Demangel C, Malavaud B, et al. Identification of a peptide blocking vascular endothelial growth factor (VEGF)-mediated angiogenesis. EMBO J. 2000;19(7):1525-1533.

50. Katanasaka Y, Ishii T, Asai T, et al. Cancer antineovascular therapy with liposome drug delivery systems targeted to BiP/GRP78. Int $J$ Cancer. 2010;127(11):2685-2698.

51. Li Y, Foss CA, Summerfield DD, et al. Targeting collagen strands by photo-triggered triple-helix hybridization. Proc Natl Acad Sci U S A. 2012;109(37):14767-14772.

52. Rothenfluh DA, Bermudez H, O’Neil CP, Hubbell JA. Biofunctional polymer nanoparticles for intra-articular targeting and retention in cartilage. Nat Mater. 2008;7(3):248-254.

53. Chen Y. Photo-affinity labeling strategy to study the binding site of G protein-coupled receptors. Front Chem China. 2011;6(3):200-205. 
54. Zhang Y, Xie Z, Wang L, et al. Mutagenesis and computer modeling studies of a GPCR conserved residue W5.43(194) in ligand recognition and signal transduction for CB2 receptor. Int Immunopharmacol. 2011;11(9):1303-1310.

55. Guiellemin R. Peptides in the brain: the new endocrinology of the neurons. Science. 1978;202:390-402.

56. Lamberts SW. Octreotide: The next decade. Bristol UK: BioScientifica; 1999.

57. Melacini G, Zhu Q, Goodman M. Multiconformational NMR analysis of sandostatin (octreotide): equilibrium between beta-sheet and partially helical structures. Biochemistry. 1997;36(6):1233-1241.

58. de Jong M, Breeman WA, Kwekkeboom DJ, Valkema R, Krenning EP. Tumor imaging and therapy using radiolabeled somatostatin analogues. Acc Chem Res. 2009;42(7):873-880.

59. Okarvi SM. Peptide-based radiopharmaceuticals and cytotoxic conjugates: potential tools against cancer. Cancer Treat Rev. 2008; 34(1):13-26.

60. Barragán F, Carrion-Salip D, Gómez-Pinto I, et al. Somatostatin subtype-2 receptor-targeted metal-based anticancer complexes. Bioconjug Chem. 2012;23(9):1838-1855.

61. Morisco A, Accardo A, Gianolio E, Tesauro D, Benedetti E, Morelli G. Micelles derivatized with octreotide as potential target-selective contrast agents in MRI. J Pept Sci. 2009;15(3):242-250.

62. Accardo A, Morisco A, Gianolio E, et al. Nanoparticles containing octreotide peptides and gadolinium complexes for MRI applications. J Pept Sci. 2011;17(2):154-162.

63. Helbok A, Rangger C, von Guggenberg E, et al. Targeting properties of peptide-modified radiolabeled liposomal nanoparticles. Nanomedicine. 2012;8(1):112-118.

64. Petersen AL, Binderup T, Jølck RI, et al. Positron emission tomography evaluation of somatostatin receptor targeted 64Cu-TATE-liposomes in a human neuroendocrine carcinoma mouse model. J Control Release. 2012;160(2):254-263.

65. Zhang Y, Zhang H, Wang X, Wang J, Zhang X, Zhang Q. The eradication of breast cancer and cancer stem cells using octreotide modified paclitaxel active targeting micelles and salinomycin passive targeting micelles. Biomaterials. 2012;33(2):679-691.

66. Zhou JJ, Liu J, Xu B. Relationship between lactone ring forms of HCPT and their antitumor activities. Acta Pharmacol Sin. 2001;22(9):827-830.

67. Su Z, Shi Y, Xiao Y, et al. Effect of octreotide surface density on receptor-mediated endocytosis in vitro and anticancer efficacy of modified nanocarrier in vivo after optimization. Int $J$ Pharm. 2013;447(1-2):281-292.

68. Su Z, Niu J, Xiao Y, et al. Effect of octreotide-polyethylene glycol(100) monostearate modification on the pharmacokinetics and cellular uptake of nanostructured lipid carrier loaded with hydroxycamptothecine. Mol Pharm. 2011;8(5):1641-1651.

69. Strock CJ, Park JI, Rosen DM, et al. Activity of irinotecan and the tyrosine kinase inhibitor CEP-751 in medullary thyroid cancer. $J$ Clin Endocrinol Metab. 2006;91(1):79-84.

70. Iwase Y, Maitani Y. Octreotide-targeted liposomes loaded with CPT-11 enhanced cytotoxicity for the treatment of medullary thyroid carcinoma. Mol Pharm. 2011;8(2):330-337.

71. LiuY, Sun J, Zhang P, He Z. Amphiphilic polysaccharide-hydrophobicized graft polymeric micelles for drug delivery nanosystems. Curr Med Chem. 2011;18(17):2638-2648.

72. Zou A, Huo M, Zhang Y, et al. Octreotide-modified N-octyl-O, $\mathrm{N}$-carboxymethyl chitosan micelles as potential carriers for targeted antitumor drug delivery. J Pharm Sci. 2012;101(2):627-640.

73. Zou A, Chen Y, Huo M, et al. In vivo studies of octreotidemodified N-octyl-O, N-carboxymethyl chitosan micelles loaded with doxorubicin for tumor-targeted delivery. J Pharm Sci. 2013;102(1):126-135.

74. Huo M, Zou A, Yao C, et al. Somatostatin receptor-mediated tumortargeting drug delivery using octreotide-PEG-deoxycholic acid conjugate-modified $\mathrm{N}$-deoxycholic acid-O, N-hydroxyethylation chitosan micelles. Biomaterials. 2012;33(27):6393-6407.
75. Sun M, Wang Y, Shen J, Xiao Y, Su Z, Ping Q. Octreotide-modification enhances the delivery and targeting of doxorubicin-loaded liposomes to somatostatin receptors expressing tumor in vitro and in vivo. Nanotechnology. 2010;21(47):475101.

76. Zhang J, Jin W, Wang X, Wang J, Zhang X, Zhang Q. A novel octreotide modified lipid vesicle improved the anticancer efficacy of doxorubicin in somatostatin receptor 2 positive tumor models. Mol Pharm. 2010;7(4):1159-1168.

77. Accardo A, Mangiapia G, Paduano L, Morelli G, Tesauro D. Octreotide labeled aggregates containing platinum complexes as nanovectors for drug delivery. J Pept Sci. 2013;19(4):190-197.

78. Dai W, Jin W, Zhang J, et al. Spatiotemporally controlled co-delivery of anti-vasculature agent and cytotoxic drug by octreotide-modified stealth liposomes. Pharm Res. 2012;29(10):2902-2911.

79. De Jong WH, Borm PJ. Drug delivery and nanoparticles: applications and hazards. Int J Nanomedicine. 2008;3(2):133-149.

80. Surujpaul PP, Gutiérrez-Wing C, Ocampo-García B, et al. Gold nanoparticles conjugated to [Tyr3]octreotide peptide. Biophys Chem. 2008;138(3):83-90.

81. Mendoza-Nava H, Ferro-Flores G, Ocampo-García B, et al. Laser heating of gold nanospheres functionalized with octreotide: in vitro effect on HeLa cell viability. Photomed Laser Surg. 2013;31(1):17-22.

82. Walsh JH. Gastrin. In: Walsh JH, Dockray GJ, editors. Gut peptides: Biochemistry and Physiology. New York: Raven Press, Ltd; 1994: 75-121.

83. Wank SA, Pisegna JR, de Weerth A. Brain and gastrointestinal cholecystokinin receptor family: structure and functional expression. Proc Natl Acad Sci U S A. 1992;89(18):8691-8695.

84. Aloj L, Aurilio M, Rinaldi V, et al. Comparison of the binding and internalization properties of 12 DOTA-coupled and ${ }^{111}$ In-labelled CCK2/gastrin receptor binding peptides: a collaborative project under COST Action BM0607. Eur J Nucl Med Mol Imaging. 2011;38(8):1417-1425.

85. Pellegrini M, Mierke DF. Molecular complex of cholecystokinin-8 and $\mathrm{N}$-terminus of the cholecystokinin A receptor by NMR spectroscopy. Biochemistry. 1999;38(45):14775-14783.

86. Morelli G, De Luca S, Tesauro D, et al. CCK8 peptide derivatized with diphenylphosphine for rhenium labelling: synthesis and molecular mechanics calculations. J Pept Sci. 2002;8(7):373-381.

87. Accardo A, Morisco A, Tesauro D, Pedone C, Morelli G. Naposomes: a new class of peptide-derivatized, target-selective multimodal nanoparticles for imaging and therapeutic applications. Ther Deliv. 2011;2(2):235-257.

88. Vaccaro M, Mangiapia G, Paduano L, et al. Structural and relaxometric characterization of peptide aggregates containing gadolinium complexes as potential selective contrast agents in MRI. Chemphyschem. 2007;8(17):2526-2538.

89. Accardo A, Tesauro D, Aloj L, et al. Peptide-containing aggregates as selective nanocarriers for therapeutics. ChemMedChem. 2008;3(4): 594-602.

90. Accardo A, Tesauro D, Mangiapia G, Pedone C, Morelli G. Nanostructures by self-assembling peptide amphiphile as potential selective drug carriers. Biopolymers. 2007;88(2):115-121.

91. Morisco A, Accardo A, Tesauro D, Palumbo R, Benedetti E, Morelli G. Peptide-labeled supramolecular aggregates as selective doxorubicin carriers for delivery to tumor cells. Biopolymers. 2011;96: $88-96$.

92. Cuttitta F, Carney DN, Mulshine J, et al. Bombesin-like peptides can function as autocrine growth factors in human small-cell lung cancer. Nature. 1985;316(6031):823-826.

93. Patel O, Shulkes A, Baldwin GS. Gastrin-releasing peptide and cancer. Biochim Biophys Acta. 2006;1766(1):23-41.

94. Bunnett G. Gastrin-releasing peptide. In: Walsh JH, Dockray GJ, editors. Gut Peptides: Biochemistry and Physiology. New York: Raven Press, Ltd; 1994:423-445.

95. Smith CJ, Volkert WA, Hoffman TJ. Radiolabeled peptide conjugates for targeting of the bombesin receptor superfamily subtypes. Nucl Med Biol. 2005;32(7):733-740. 
96. Parry JJ, Kelly TS, Andrews R, Rogers BE. In vitro and in vivo evaluation of 64Cu-labeled DOTA-linker-bombesin(7-14) analogues containing different amino acid linker moieties. Bioconjug Chem. 2007;18(4):1110-1117.

97. Martin AL, Hickey JL, Ablack AL, Lewis JD, Luyt LG, Gillies ER. Synthesis of bombesin-functionalized iron oxide nanoparticles and their specific uptake in prostate cancer cells. J Nanopart Res. 2009;12(5):1599-1608.

98. Accardo A, Mansi R, Morisco A, et al. Peptide modified nanocarriers for selective targeting of bombesin receptors. Mol Biosyst. 2010;6(5): $878-887$.

99. Accardo A, Salsano G, Morisco A, et al. Peptide-modified liposomes for selective targeting of bombesin receptors overexpressed by cancer cells: a potential theranostic agent. Int J Nanomedicine. 2012;7: 2007-2017.

100. Mansi R, Wang X, Forrer F, et al. Evaluation of a 1,4,7,10tetraazacyclododecane-1,4,7,10-tetraacetic acid-conjugated bombesinbased radioantagonist for the labeling with single-photon emission computed tomography, positron emission tomography, and therapeutic radionuclides. Clin Cancer Res. 2009;15(16):5240-5249.

101. Accardo A, Mansi R, Salzano G, et al. Bombesin peptide antagonist for target-selective delivery of liposomal doxorubicin on cancer cells. J Drug Target. 2013;21:240-249.

102. Zharov VP, Galitovskaya EN, Johnson C, Kelly T. Synergistic enhancement of selective nanophotothermolysis with gold nanoclusters: potential for cancer therapy. Lasers Surg Med. 2005;37(3): 219-226.

103. Chanda N, Kattumuri V, Shukla R, et al. Bombesin functionalized gold nanoparticles show in vitro and in vivo cancer receptor specificity. Proc Natl Acad Sci U S A. 2010;107(19):8760-8765.
104. Hosta-Rigau L, Olmedo I, Arbiol J, Cruz LJ, Kogan MJ, Albericio F. Multifunctionalized gold nanoparticles with peptides targeted to gastrin-releasing peptide receptor of a tumor cell line. Bioconjug Chem. 2010;21(6):1070-1078.

105. Dasgupta P, Sun J, Wang S, et al. Disruption of the Rb - Raf-1 interaction inhibits tumor growth and angiogenesis. Mol Cell Biol. 2004;24(21):9527-9541.

106. Nagy A, Schally AV. Targeting of cytotoxic luteinizing hormonereleasing hormone analogs to breast, ovarian, endometrial, and prostate cancers. Biol Reprod. 2005;73(5):851-859.

107. HeY, Zhang L, Song C. Luteinizing hormone-releasing hormone receptor-mediated delivery of mitoxantrone using LHRH analogs modified with PEGylated liposomes. Int J Nanomedicine. 2010;5:697-705.

108. He Y, Zhang L, Song C. Luteinizing hormone-releasing hormone receptor-mediated delivery of mitoxantrone using LHRH analogs modified with PEGylated liposomes. Int J Nanomedicine. 2010;5: 697-705

109. Hermey G. The Vps10p-domain receptor family. Cell Mol Life Sci. 2009;66(16):2677-2689.

110. Falciani C, Fabbrini M, Pini A, et al. Synthesis and biological activity of stable branched neurotensin peptides for tumor targeting. Mol Cancer Ther. 2007;6(9):2441-2448.

111. Falciani C, Accardo A, Brunetti J, et al. Target-selective drug delivery through liposomes labeled with oligobranched neurotensin peptides. ChemMedChem. 2011;6(4):678-685.

112. Falciani C, Brunetti J, Lelli B, et al. Nanoparticles exposing neurotensin tumor-specific drivers. J Pept Sci. 2013;19(4):198-204.
International Journal of Nanomedicine

\section{Publish your work in this journal}

The International Journal of Nanomedicine is an international, peerreviewed journal focusing on the application of nanotechnology in diagnostics, therapeutics, and drug delivery systems throughout the biomedical field. This journal is indexed on PubMed Central,

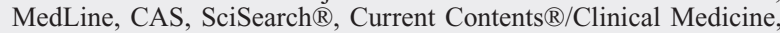

\section{Dovepress}

Journal Citation Reports/Science Edition, EMBase, Scopus and the Elsevier Bibliographic databases. The manuscript management system is completely online and includes a very quick and fair peer-review system, which is all easy to use. Visit http://www.dovepress.com/ testimonials.php to read real quotes from published authors. 